IZA DP No. 5340

Two-Tier Labor Markets in the Great Recession:

France vs. Spain

Samuel Bentolila

Pierre Cahuc

Juan J. Dolado

Thomas Le Barbanchon

November 2010 


\title{
Two-Tier Labor Markets in the Great Recession: France vs. Spain
}

\author{
Samuel Bentolila \\ CEMFI \\ Pierre Cahuc \\ Ecole Polytechnique, CREST and IZA \\ Juan J. Dolado \\ Universidad Carlos III and IZA \\ Thomas Le Barbanchon \\ Ecole Polytechnique and CREST
}

Discussion Paper No. 5340

November 2010

IZA

P.O. Box 7240

53072 Bonn

Germany

Phone: +49-228-3894-0

Fax: +49-228-3894-180

E-mail: iza@iza.org

Any opinions expressed here are those of the author(s) and not those of IZA. Research published in this series may include views on policy, but the institute itself takes no institutional policy positions.

The Institute for the Study of Labor (IZA) in Bonn is a local and virtual international research center and a place of communication between science, politics and business. IZA is an independent nonprofit organization supported by Deutsche Post Foundation. The center is associated with the University of Bonn and offers a stimulating research environment through its international network, workshops and conferences, data service, project support, research visits and doctoral program. IZA engages in (i) original and internationally competitive research in all fields of labor economics, (ii) development of policy concepts, and (iii) dissemination of research results and concepts to the interested public.

IZA Discussion Papers often represent preliminary work and are circulated to encourage discussion. Citation of such a paper should account for its provisional character. A revised version may be available directly from the author. 
IZA Discussion Paper No. 5340

November 2010

\section{ABSTRACT}

\section{Two-Tier Labor Markets in the Great Recession: France vs. Spain ${ }^{*}$}

This paper analyzes the strikingly different response of unemployment to the Great Recession in France and Spain. Their labor market institutions are similar and their unemployment rates just before the crisis were both around $8 \%$. Yet, in France, unemployment rate has increased by 2 percentage points, whereas in Spain it has shot up to $19 \%$ by the end of 2009 . We assess what part of this differential is due to the larger gap between the dismissal costs of permanent and temporary contracts and the less restrictive rules regarding the use of the latter contracts in Spain. Using a calibrated search and matching model, we estimate that about $45 \%$ of the surge in Spanish unemployment could have been avoided had Spain adopted French employment protection legislation before the crisis started.

JEL Classification: $\quad H 29, \mathrm{~J} 23, \mathrm{J38}, \mathrm{J41}, \mathrm{J} 64$

Keywords: $\quad$ temporary contracts, unemployment, Great Recession

Corresponding author:

Pierre Cahuc

Department of Economics

Ecole Polytechnique

91128 Palaiseau Cedex

France

E-mail: pierre.cahuc@polytechnique.edu

\footnotetext{
* A preliminary version of this paper was prepared for the Fedea Annual Policy Conference, Madrid, 28-30 October 2009. We are very grateful to Florentino Felgueroso, J. Victor Rios-Rull, Gilles SaintPaul, and Etienne Wasmer for their insightful suggestions that greatly improved the paper; useful comments are also acknowledged from participants at several seminars and conferences. We also wish to thank David Colino for excellent research assistance, and Brindusa Anghel and J. Ignacio García-Pérez for help with data.
} 


\section{Introduction}

The goal of this paper is to explain the strikingly different response of Spanish unemployment relative to France, during the so-called Great Recession triggered by the financial and economic crisis in 2007-08. We focus on a comparison with France because both economies share similar labor market institutions (employment protection legislation, unemployment benefits, wage bargaining, etc.) and exhibited very similar unemployment rates, around 8\%, just before the crisis started. However, while the French unemployment rate has only risen to $10 \%$ during the slump, Spanish unemployment -after falling from $22 \%$ in 1994 to $8 \%$ in 2007, when Spain was creating a large share of all new jobs in the European Union (EU) - has surged to $19 \%$ by the end of 2009. Our main contribution in this paper is to analyze which part of this very different response can be attributed to what we identify as the main difference between the labor market regulations of these two economies: a larger gap between the dismissal costs of workers with permanent and temporary contracts and a much laxer regulation on the use of temporary contracts in Spain than in France. We argue that these differences, often ignored in cross-country comparisons of overall employment protection legislation (EPL hereafter), could explain up to $45 \%$ of the much higher rise of Spanish unemployment.

France and Spain allow us to tell an interesting tale of two neighboring countries. Both are among those EU economies which most decidedly promoted temporary contracts in the past to achieve higher labor market flexibility. Creating a two-tier labor market is often seen as a politically viable way of achieving this goal when there is great resistance from protected insider workers (see Saint-Paul, 1996 and 2000). However, temporary employment is much more important in Spain, reaching around one-third of employees until recently, whereas this share has been slightly below 15\% in France. Therefore it seems natural to ask whether the markedly different unemployment impact of the recession is due to this difference, controling for other potential explanatory factors.

To explore these issues, following previous work by Blanchard and Landier (2002) and Cahuc and Postel-Vinay (2002), we propose a search and matching model with endoge- 
nous job destruction à la Mortensen-Pissarides (1994) which allows for the distinction between permanent and temporary jobs. In our model, firms can offer both types of contracts subject to different EPL, and the latter can be transformed into permanent contracts at their expiration, the rest being terminated at low or no cost at all. It is now well understood that facilitating the creation of temporary jobs promotes job creation but increases job destruction, leading to an ambiguous effect on unemployment. However, one result that has drawn less attention in this strand of the literature is that the increase in job destruction induced by temporary jobs may have a larger adverse impact on unemployment when the gap in firing costs in favor of permanent contracts is high enough. The higher is this gap, the lower will be the proportion of temporary jobs transformed into permanent jobs, because much larger firing costs for the latter induce employers to use temporary jobs in sequence, especially if restrictions on their use are mild, rather than converting them into long-term contracts. This implies that facilitating a widespread use of flexible temporary contracts is more likely to raise unemployment in labor markets already regulated by stringent permanent job security provisions.

The issue that labor market volatility increases with the introduction of flexible temporary jobs has been stressed by Bentolila and Saint-Paul (1992) and Boeri and Garibaldi (2007), who argue that two-tier labor market reforms have a transitional honeymoon, jobcreating effect which typically precedes reductions in employment as a result of temporary workers' lower labor productivity. Deepening this line of research, Sala et al. (2009) and Costain et al. (2010) have recently studied the cyclical properties of dual labor markets subject to limitations on the use of temporary contracts. In particular, they explore whether flexibility at the margin is the reason why labor markets with a relatively high degree of EPL may display similar volatility as fully flexible ones. While Sala et al. (2009) find that this partial flexibility leads to an intermediate situation, in terms of unemployment volatility, between fully regulated and fully deregulated labor markets, Costain et al. (2010), focusing on the Spanish case, estimate that unemployment fluctuates $22 \%$ more in the prevailing dual labor market than it would in a unified economy with a sin- 
gle contract. In common with these authors, our approach focuses on the interactions between aggregate productivity shocks and EPL, including the regulation of temporary jobs. However, while their work focuses on labor market dynamics over the business cycle following a sequence of shocks, ours relies exclusively on a single shock which captures a particularly relevant event, as is the case of the Great Recession. This simpler approach has the advantage of enabling us to be more precise about the role played by specific features of labor contracts that can account for the strikingly different response of France and Spain to this global crisis.

From this perspective, our model differs from those of Sala et al. (2009) and Costain et al. (2010) in three main respects. First, they assume that temporary jobs can be destroyed at any time. However, since regulations impose that temporary jobs cannot be destroyed before their date of termination, which is defined when the job is created, our model accounts for this feature. Second, we assume that time is needed to destroy permanent jobs, whereas they assume that these jobs can be instantly destroyed. ${ }^{1}$ Our assumption is consistent with regulations which impose advance notice and induce delays in job destruction due to the time needed to settle legal disputes. Third, we also differ in how wage bargaining is modeled. In contrast with these authors, we do not assume that employers have to pay firing costs if they do not agree on the initial wage contract once they are matched with a worker. Instead, we assume that firing costs are paid when workers and employers separate only if a contract has already been signed. As Ljungqvist (2002) has shown, assuming that firing costs are paid by the employer if there is a separation in the initial bargain -when the job starts- magnifies the impact of firing costs on unemployment. We think that our assumption is more plausible and it captures better the institutions of France and Spain, where labor contracts are renegotiated by mutual agreement (Malcomson, 1999; Cahuc et al., 2006).

The rest of the paper is structured as follows. We start by documenting in Section 2 the relative performance of the French and Spanish labor markets during the crisis vis-à-

\footnotetext{
${ }^{1}$ Garibaldi (1998) incorporated advance notice in a model with endogenous job destruction.
} 
vis the preceding expansion. In Section 3 we present the main features of the regulations affecting these two labor markets, devoting special attention to the EPL gap between permanent and temporary contracts, and discuss how strong duality in labor markets can affect sectoral specialization, labor mobility, and mismatch. In Section 4, we introduce a stylized search and matching model focusing on equilibrium behavior of firms and workers in an economy with both temporary and permanent contracts, where it is possible to transform the former into the latter. In Section 5, we start by analyzing the extent to which our calibrated model, with each country maintaining their respective prevailing institutions before the slump, can account for the change in the performance of their labor markets from the boom (represented by 2005-2007) to the recession (2008-2009), following a common adverse shock affecting both economies. We then compute the share of the rise in Spanish unemployment during the crisis which is due to differences in EPL with France by running counterfactual simulations on how it would have fared had Spain adopted French EPL before the recession started. Section 6 concludes.

\section{Labor market performance before and during the crisis}

As depicted in Figure 1, France and Spain had an unemployment rate of $3.8 \%$ at the end of 1976. From then on, both rates rose in tandem but the Spanish rate was always on top and showed much higher volatility. The difference increased up until the end of 1994 and shrank thereafter. By the end of 2005, the two unemployment rates seemed to have come full circle, reaching similar values around $8 \%$. Convergence was however a mirage. Since the onset of the worldwide recession, unemployment in Spain has shot up from $8 \%$ to $19 \%$ while French unemployment kept on falling, to $7.2 \%$, and then has grown to $9.3 \%$. In the rest of this section, we briefly discuss some potential explanations for this strikingly different response.

Table 1 presents a few key labor-market magnitudes from 1998:1 to 2007:4, an expansion, and 2008:1-2009:4, a recession. It becomes apparent that, throughout the boom, 
both labor force and employment growth rates have been much higher in Spain. It is the Spanish figures that are remarkable, while the French ones are typical of the euro area experience. While the share of foreigners in the French labor force was stable, the labor force in Spain received a boost from large immigration flows amounting to around $1 \%$ of the population per year, and also from an increase in the female labor participation rate -for natives that rate increased by 8.4 percentage points (pp.) against 2.9 pp. in France. ${ }^{2}$ Focusing on private sector employees, it can be observed that the employment surge in Spain stems especially from construction and market services $(8.1 \%$ and $6.8 \%$ per year, respectively). The corresponding figures were more moderate in France, including a fall in manufacturing employment. The disparity was reinforced by the behavior of working hours per employee: the implementation of the 35 hours law caused a significant drop in France, while they were stable in Spain

In the downturn, growth in the French labor force has hardly altered, while in Spain it has experienced a significant slowdown. France has suffered a small employment fall $(0.3 \%$ p.a.), though much more in terms of private sector employees (1.6\%), which is dwarfed by the Spanish free fall (4.6\% p.a.), especially in the private sector $(5.7 \%)$. The latter stems especially from a collapse of almost $20 \%$ p.a. (i.e. $36 \%$ in total) of employment in construction and a $10.8 \%$ drop in manufacturing.

As discussed earlier, it is very hard to explain the extreme volatility in the Spanish labor market without recourse to the prevailing types of contracts. As shown in Table 1, temporary contracts in 1998 represented almost 14\% of employees in France and 33\% in Spain. During the expansionary period 1998-2007, the vast majority of (quarterly) flows from unemployment to salaried employment were under these contracts: $78.4 \%$ in France and $87.2 \%$ in Spain. Correspondingly, they also represented the majority of employment outflows, in particular (from administrative sources): $88 \%$ in France and $80.1 \%$ in Spain. Consequently, the brunt of job losses since the end of 2007 has been borne by temporary jobs: 277.000 net jobs where destroyed in France, while actually 324.000 temporary jobs

\footnotetext{
${ }^{2}$ See Bentolila et al. (2008a) for a discussion of immigration flows in Spain.
} 
disappeared, while the corresponding figures for Spain are simply stunning: 1.33 and 1.38 million jobs, respectively.

Table 1 also shows that the share of temporary jobs in Spain has slightly decreased, from $33 \%$ to $31 \%$, between 1998 and 2007. One may wonder how this matches with the idea that the drop in unemployment is a result of the spread of temporary jobs over this expansionary period. There are two explanations for this fact. On the one hand, this was a very long expansion where Spanish GDP was growing at an average annual rate of 3.7\%. As pointed out by Wasmer (1999), such a long expansionary phase induces a so-called capitalization effect whereby high growth increases future profits and thus strengthens firms' incentives to increasingly offer permanent contracts so as to retain their workers. On the other hand, the Spanish government passed a labor reform in 1997 aiming to reduce the severance pay gap between permanent and temporary contracts. They did so through two new policy measures: a new type of permanent contract with lower severance pay (see next Section), unavailable for males aged 31-44 years old unemployed for less than one year, and the introduction of severance pay of 8 days of wages upon termination of temporary and interim contracts (previously there was none). The 1997 reform also included generous social security contribution rebates for hiring under the new permanent contracts. Thus, in principle, the latter became more attractive. However, these changes induced a very small drop in the rate of temporary employment, since the lower severance pay does not apply to unfair dismissals for disciplinary reasons (e.g. worker misconduct), which are the ones often employed by firms to avoid long and uncertain legal disputes on the reason for the dismissals (see below). Therefore, even for these less-protected contracts, firms ended up paying a high severance pay. ${ }^{3}$

\footnotetext{
${ }^{3}$ Indeed, Garcia-Perez and Rebollo (2009) document that, in practice, most firms use this contract to pocket the subsidy, usually dismissing the employee under the standard procedure, as soon as the minimum job duration required by law is reached.
} 


\section{Labor institutions in France and Spain}

In this section, the institutional settings of the French and Spanish labor markets are briefly reviewed. We focus on EPL, unemployment benefits and wage bargaining. We argue that the main difference arises from the higher EPL gap between permanent and temporary workers in Spain than in France. Finally, we examine labor mobility, which we document to be much lower in Spain, partly as a result of the high uncertainty associated with the use of temporary contracts and the low conversion rates to permanent ones induced by the large EPL gap.

\subsection{Employment protection}

As mentioned earlier, France and Spain are among the countries where governments have, through their regulations, more strongly promoted temporary contracts to increase labor market flexibility aimed at reducing unemployment.

Table A1 in the Appendix presents the key features of regulations concerning dismissals in the two countries. Permanent contracts are subject to advance notice periods and severance pay. ${ }^{4}$ Severance pay for economic reasons in France is equal to 6 days of wages per year of service (the latter clause is understood hereafter) plus 0.08 extra days for tenure above 10 years. In Spain that pay is equal to 20 days, whereas severance pay for unfair dismissal is equal to 45 days. From these figures it may seem that firing permanent employees is much cheaper in France than in Spain, but this would be misleading, since there are additional important components of firing costs beside severance pay. For example, in France, as soon as a worker reaches a 2-year seniority the notice period doubles, while in Spain most firms avoid it in exchange for a much higher severance pay. Likewise, administrative approval is required for collective dismissals in Spain (roughly

\footnotetext{
${ }^{4}$ In France, this includes the regular permanent contract or contrat à durée indeterminée (CDI) and the new employment contract (contrat nouvelles embauches, CNE, which has different severance pay and other conditions) introduced in 2005 for small firms (see Cahuc and Carcillo, 2006). In Spain it includes both regular permanent contracts and the subsidized contrato indefinido de fomento del empleo In principle, the latter has lower severance pay but, as argued above, in fact most dismissals incur the penalty rate for unfair dismissals.
} 
those involving $10 \%$ of an establishment's staff), which is almost impossible to obtain without worker representatives' agreement to the dismissal in advance (again in exchange for higher severance pay).

Computing overall measures of EPL is not an easy task. Let us consider the widely used OECD (2004) index of the strictness of EPL for 2003, which ranges from 0 to 6, with higher scores indicating stricter regulation. This indicator gives a score of 2.5 for France and 2.6 for Spain regarding protection of permanent jobs, 3.6 for France and 3.5 for Spain on regulation of temporary jobs, and 2.1 for France and 3.1 for Spain on regulation of collective dismissals. The overall EPL score is 3.0 for France and 3.1 for Spain (where the US has the lowest value, 0.7, and Portugal and Turkey the highest, 4.3). Hence, both countries are ranked in the middle-high range, with Spain appearing only slightly more regulated than France. However, there are good reasons to think that this average EPL index, based on legal regulations and not on their implementation, does not capture Spanish EPL satisfactorily. As argued below, de facto EPL of temporary jobs is much weaker in Spain than in France, whereas the opposite holds for EPL of permanent jobs.

Moreover, economic theory on the effects of firing costs on employment tells us that what matters is not severance pay per se, which is a transfer from the firm to the worker and may therefore be compensated for in the wage bargain (Lazear, 1990). Rather, since the probability that workers will contest dismissals is very high, what matter are other costs that are not appropriated by firms and workers but are generated by third agents, such as labor courts and labor authorities, i.e., the so-called red-tape costs. For example, severance pay offered by firms in exchange for a quick resolution of dismissals in France is typically higher than statutory severance or that agreed in collective bargains. In Spain, the extra cost does not only apply to collective dismissals but also to individual ones. In effect, since firms that go to court lose in 3 out of 4 cases on average, they typically find it more profitable to allege disciplinary reasons even if they think that dismissals are justified on economic grounds. Proceeding in this way they do not need to satisfy the notice period and, upon immediately acknowledging the dismissal to be unfair, they avoid 
going to court by paying upfront the penalty of 45-days severance pay. ${ }^{5}$ In applying our theoretical model to these two labor markets, we adopt a conservative strategy and only focus on the distortionary effect of the firing tax component of severance pay. Accordingly, we will use estimated red-tape costs which, as will be discussed in Section 5.2, turn out to be $50 \%$ higher in Spain than in France, though the notice period is much shorter, an EPL feature also accounted for in our calibrated model.

Further, the use of temporary contracts is rather more limited in France than in Spain. ${ }^{6}$ In France, they can only be used in nine specific cases: for replacing an employee who is absent or temporarily working part time, to transitorily replace an employee whose job is either going to be suppressed or filled by another permanent worker, and for temporary increases in the firm's activity, seasonal activities, and jobs in certain sectors (forestry, naval, entertainment, teaching, survey-making, professional sports, etc.). In Spain, temporary contracts may be used for objective reasons (specific work, accumulation of tasks, replacement, etc.), for training, to hire disabled workers, and to cover the part of the working day left uncovered by an employee close to retirement. De facto, however, there are no restrictions: employers are hardly monitored by the authorities to ensure that they comply with the alleged reasons for hiring under temporary contracts. Finally, while in both countries the maximum duration of temporary contracts is 24 months, uncertaincompletion jobs (e.g., in the much more prominent construction sector in Spain before the crisis) may lawfully last for an indeterminate period.

In sum, the previous discussion points out that, in contrast with OECD rankings, EPL for permanent contracts is more stringent in Spain than in France, while the opposite is true for temporary contracts. Thus overall EPL may look similar but this aggregate

\footnotetext{
${ }^{5}$ This option has been available to firms in Spain since the Law 45/2002 was passed and it implies severance payments of 45 days of wages per year of service, with a maximum of 42 months' wages.

${ }^{6}$ In this paper we use the term "temporary contracts" to denote all sorts of non-permanent contracts. We focus on fixed-term contracts, captured by the contrat a duration determinée (CDD) in France and the contrato temporal in Spain. There are several types of temporary contracts in Spain. And other nonpermanent jobs exist in France, such as temporary jobs proper (emploi interimaire or emploi temporaire). Moreover, in both countries there are also jobs intermediated by temporary work agencies and most apprenticeship contracts are temporary as well. Empirically we shall consider all of these as temporary contracts.
} 
indices hide the fact that the gap in EPL between the two types of contracts turns out to be much higher in Spain. ${ }^{7,8}$

\subsection{Unemployment benefits}

Unemployment insurance in France features a gross replacement ratio of $57.4 \%$ of the preceding year's wage. ${ }^{9}$ In Spain, the replacement ratio decreases over time: it is $70 \%$ for the first 6 months and drops to $60 \%$ thereafter. Thus, at least at the beginning of unemployment spells, the Spanish system looks more generous than the French one. In comparing benefits, however, it is crucial to take into account personal characteristics and to consider replacement rates net of taxes. Thus, according to the OECD Benefits and Wages database (March 2006 update), the net replacement rate in 2004 for an average production worker who was married, whose partner did not work, and who had no children was equal to $69 \%$ in both countries. Likewise, if the same worker was married with a working partner and had two children, again the replacement rates do not differ much: $84 \%$ in France and $87 \%$ in Spain.

In France, the length of benefits is the same as the worker's contribution period, with a maximum duration of 23 months (and higher for workers older than 50 years old). In Spain, benefit length increases in steps that imply durations going from $22 \%$ to one-third of the contribution period, which has to be of at least 12 months, with a maximum duration of 24 months. In computing a measure of unemployment benefits for our simulations we take into account statutory benefits and coverage, which is affected by duration rules.

Workers who exhaust unemployment insurance or are ineligible for it are entitled to so-called "minimum integration income" (Revenu Minimum d'Insertion, RMI) in France, amounting to $€ 454.63$ (the minimum wage net of social contribution for full time work-

\footnotetext{
${ }^{7}$ For more specific details on the level and structure of firing costs in France, see Cahuc and PostelVinay (2002) and Cahuc and Carcillo (2006), and Bentolila and Jimeno (2006) and Bentolila et al. (2008b) for Spain.

${ }^{8}$ A labor market reform has been approved in Spain in September 2010, which has altered severance pay for permanent and temporary contracts. This reform is however outside the period we examine and its effects will only be felt over time.

${ }^{9} \mathrm{Or}$, if it is higher, $40.4 \%$ of the wage plus a fixed amount (currently around 330 euros per month).
} 
ers being equal to $€ 1,042$ ) and $€ 681.9$ for a couple (plus child benefits). ${ }^{10}$ In Spain, the assistance benefit is equal to $80 \%$ of the so-called "Multi-Purpose Public Income Indicator", which in 2008 amounted to $€ 413.5$ (around $23 \%$ of gross earnings in the private non-agricultural sector), with higher benefits for workers with family responsibilities. It is means-tested at the level of the benefit. Additional welfare benefits are available in some regions (for example in Madrid they amount to €370) but coverage is typically low.

\subsection{Wage bargaining}

Collective wage bargaining is similar in the two countries. It can be argued that this is the result of Spain adopting French regulations in the early 1980s, when the postdictatorship Spanish system of collective bargaining was established. In both countries, most workers are covered by collective bargaining, above $90 \%$ in France and above $80 \%$ in Spain. Bargaining takes place mostly at the industry level and there is geographical fragmentation (through industry-department agreements in France and industry-province agreements in Spain). Conditions set in above firm-level agreements are extended to all firms and workers in the relevant industry or geographical area; extension is discretionary in France and automatic in Spain.

In Spain, workers are represented by worker delegates in firms with less than 50 employees and by worker committees in firms with more than 50 employees, reflecting French practice. Unions obtain representation from firm-level elections, where voters need not be unionized. Thus, there is little incentive for workers to unionize, so that union density is very low but largely irrelevant. Both countries have the highest gaps between the coverage of collective bargaining and union density (in 2007 the latter was equal to $8 \%$ in France and $14.6 \%$ in Spain, see Visser, 2009). ${ }^{11}$ One difference, though, is that whereas in Spain there are only two nationally representative unions (CCOO and UGT), in France there

\footnotetext{
${ }^{10}$ The RMI was replaced, as of the third quarter of 2009, by the Revenue de Solidarité Actives (rSa). There is another scheme equivalent to the RMI (also open to those above 25 years old who never worked) for those who have worked before and are not eligible anymore: the Allocation de Solidarité Specifique (ASS), with an amount equivalent to the RMI.

${ }^{11}$ For more details regarding Spain see Bentolila and Jimeno (2006).
} 
are eight unions. Nonetheless, they are not equally powerful and, like in Spain, two unions are especially influential, particularly in the public sector (CGT and CDFT). Lastly, it is worth noting that, although the monthly statutory minimum wage is quite higher in France than in Spain (1,321 and 728 euros in 2009, respectively; Eurostat), the Kaitz ratio (i.e., the ratio between the minimum and the average wage) is not very different ( $41 \%$ and $50 \%$ respectively). Moreover, fewer full-time workers receive the minimum wage in Spain (about 5\% and 18\%, respectively) because wage floors are often determined in collective bargaining above the statutory level.

In sum, we believe that the two countries are not significantly different in their wage setting institutions and therefore we do not explore any potential differences in this dimension in the simulations below.

\subsection{Mismatch, sectoral specialization and labor mobility}

Besides the EPL gap, labor mobility is the other dimension in which the French and Spanish labor markets differ. ${ }^{12}$ This difference does not become apparent in job mobility, which turns out to be rather similar: average job duration is equal to 7.6 years in France and 8.2 in Spain, while the fractions of workers who have changed job in the preceding 10 years are $49 \%$ and $50 \%$, respectively. ${ }^{13}$

Yet, geographical mobility is much lower in Spain. A good starting point in documenting this difference is home leaving. The average age at which young people leave the parental home in France is around 24 years old against around 29 years old in Spain. Another striking disparity is that the fraction of people who have never moved after leaving the parental home is equal to $23 \%$ in Spain but only $8 \%$ in France. Moreover, while $30 \%$ of the French population has moved across regions, only 11\% of Spaniards have done so. Overall, the interregional migration rate for people aged 15-64 is 2.1\% in France and only $0.2 \%$ in Spain, with a wider disparity for young people (15-24 years old): $3.8 \%$ in France

\footnotetext{
${ }^{12}$ We are very grateful to Etienne Wasmer for suggesting that we take this issue into account.

${ }^{13}$ This is in spite of the higher temporary employment rate in Spain, due to its higher EPL on permanent jobs vis-à-vis France.
} 
and $0.23 \%$ in Spain. ${ }^{14}$

Low interregional mobility has affected the impact of the recession in Spain, since its regions have been hit quite differently by the crisis. Regional employment destruction growth rates of dependent employment, which range from -1\% to -13.4\% (2007:4-2009:3), are closely related to the regional shares of employment in the construction industry, which has plummeted during the recession (a 36\% nationwide reduction of employment in this sector with regional rates ranging from $18.7 \%$ to $54.7 \%$ ). This strong link is illustrated by the raw correlation coefficient between the changes in total and construction employment shares across Spanish regions, which is equal to $0.7 .{ }^{15}$

In what follows we argue that the strong dependence of the Spanish economy on the construction sector since the late 1990s (11.9\% of GDP and $13.3 \%$ of employment in 2007 , against $6.3 \%$ and $6.9 \%$ in France; Eurostat) is closely related to the existence of a dual labor market. In effect, as a result of Spain's access to the euro area in the late 1990s with a higher inflation rate than France, real interest rates fell by 6 pp., against 1.5 pp. in France, fueling a strong investment boom. These new investment projects could have taken place in either high value-added industries (like, e.g., ICT in Finland) or in low-value added ones. Investors bet rationally for the latter for at least two reasons. On the one hand, the rigid permanent contracts would have been inadequate to specialize in more innovative sectors, since higher labor flexibility is required to accommodate the higher degree of uncertainty typically associated with producing higher value-added goods (SaintPaul, 1997). On the other hand, there was a large increase in the relative endowment of unskilled labor in Spain over that period. The higher availability of low-skilled jobs through very flexible contracts since the mid-1980s led to a high dropout rate of youth from compulsory education (from $18 \%$ in 1990 to $32 \%$ in 1997) and subsequently to a huge inflow of unskilled immigrants (implying a $10 \mathrm{pp}$. increase in the foreign population rate).

\footnotetext{
${ }^{14}$ The home-leaving figure corresponds to 2007, from the Labor Force Survey, see Eurostat (2009), Figure 2.1. The subsequent figures are for 2005, from the analysis of the 2005 Eurobarometer by Vandenbrande et al. (2006), Figures 20, 23, 2 and 3, and Table 2, respectively. Lastly, the interregional migration rate corresponds to 2003, from OECD (2005).

${ }^{15}$ These figures leave out the Balearic Islands, which have an abnormally high employment level in 2009:3 due to seasonal factors related to the turism industry.
} 
Hence, as a result of this relative abundance of less-skilled labor, most firms, especially small and middle-sized ones, adopted technologies which where complementary with this type of workers, leading to a boom in the construction sector.

Low geographical mobility is a source of mismatch and higher equilibrium unemployment via reallocation rather than conventional aggregate shocks (Layard et al., 1991). This has become quite apparent in the aftermath of the recession in Spain, where unemployment rate dispersion has sharply increased. The range between the lowest and the highest regional unemployment rates, which was equal to 10.3 pp. in $2007: 4$, has risen to 15.6 pp. in 2009:4, whereas the standard deviation of those rates increased from 3 to 5 over that period. ${ }^{16}$ In sharp contrast, that range only increased in France from 9.6 pp. to 11.3 pp., while the standard deviation hardly changed, from 1.3 to $1.4 .^{17}$

Geographical mobility depends on many factors, both economic and non-economic. Institutional determinants of regional divergence in incomes and unemployment rates surely play a role. For instance, Bentolila and Dolado (1991) found, for 1962-1986 (roughly a pre-temporary employment period in Spain), that if the national unemployment rate doubled (from $10 \%$ to $20 \%$, not far from the current situation), the elasticity of interregional migration flows to regional wage and unemployment differentials halved. This estimate is likely to be similar nowadays. On the other hand, Rupert and Wasmer (2009), echoing earlier work by Oswald (1999), highlight the role of housing regulations in accounting for differences in unemployment between Europe and the US. The Spanish rental market works very poorly and is underdeveloped, representing only $12 \%$ of the housing market, against 40\% in France. Therefore, it clearly hampers regional migration (Barceló, 2006). This is due to various institutional factors, in particular a legal structure that favors tenants vs. landowners and an income tax system which heavily subsidizes owner-occupied housing (Lopez-Garcia, 2004).

Moreover, like in the case of industrial specialization, differences in EPL may be a

\footnotetext{
${ }^{16}$ This was even stronger for workers aged 16 to 24 years old. The lowest-highest unemployment rate difference increased from 19.4 to 24.7 and the standard deviation from 4.6 to 6.3 .

${ }^{17}$ France: Labor Force Survey, BDM Macro-economic Database (www.bdm.insee.fr). Spain: Labor Force Survey (www.ine.es).
} 
concomitant event to differences in labor mobility. On the one hand, there is evidence that the widespread use of temporary contracts may reduce regional migration despite its potentially beneficial effect on job creation. For example, using individual data for Spain, Antolín and Bover (1997) found that temporary employment reduces the likelihood of interregional migration. The insight is that a temporary job in a different region does not provide much job security whereas migrating means giving up, to a large extent, the support of family networks, which are a key insurance mechanism in Southern Mediterranean countries (Bentolila and Ichino, 2008). In a similar vein, Becker et al. (2010) find, with a sample of 13 European countries over 1983-2004, that youth job insecurity discourages home-leaving, whereas parental job insecurity encourages it. Thus, to the extent that permanent and temporary contracts are roughly held by older and younger workers, respectively, the much higher EPL gap in Spain would be consistent with its much lower home-leaving rate.

Overall, the above evidence indicates that the Great Recession is likely to have induced a much larger increase in mismatch in Spain than in France. Indeed, the Spanish Beveridge curve, plotted in Figure 2, confirms that this differential effect may have been rather relevant. While there seems to be a stable relationship from 1994 to 2007, there is a large outward shift during the Great Recession of both the vacancy rate and the unemployment rate, indicating growing mismatch. ${ }^{18}$ For France, data are not available on vacancy stocks, only on flows. Yet, though not reported (but available upon request), unlike in Spain, these flows show no indication, of an outward shift in the French Beveridge curve from 1997 until 2009.

\section{Model}

This section presents our search and matching model, inspired by previous work by Blanchard and Landier (2002) and Cahuc and Postel-Vinay (2002), where the seminal

\footnotetext{
${ }^{18}$ Unemployment is expressed as a percentage of the labor force whereas vacancy is in per thousand. The figures in the graph are adapted from results in Bouvet (2009) spliced with survey data from the Encuesta de Coyuntura Laboral (www.mtin.es/estadisticas/ecl/Ecl22010/SER/index.htm), which start in 2000 .
} 
Mortensen-Pissarides (1994) model with endogenous job destruction is extended to allow for the distinction between temporary and permanent jobs entailing different dismissal costs and advance notice periods.

\subsection{Model setup}

The main features of the model are as follows. First, there is a continuum of infinitelylived risk-neutral workers and firms, with a common discount rate $r>0$. The measure of workers is normalized to 1 .

Job matches have an idiosyncratic productivity distribution $F(\varepsilon)$, drawn over the support $[\underline{\varepsilon}, \bar{\varepsilon}] .{ }^{19}$ The idiosyncratic productivity shocks follow a Poisson distribution with incidence rate $\mu$. In line with Pissarides (2000), it is assumed for simplicity that all new jobs start at the highest productivity $\bar{\varepsilon}^{20}$

There are two types of jobs, temporary and permanent, both endowed with the same productivity distribution. Trying to mimic realistic wage bargaining procedures, it is assumed that wages are only renegotiated in permanent jobs but not in temporary jobs, where wages are often fixed for the whole duration of the contract. Unemployed workers have access to temporary jobs with probability $p$, exogenously set as EPL policy, and to initial permanent jobs with probability $(1-p)$. Temporary jobs are terminated with per unit of time probability $\lambda$, at which point firms can either convert them to permanent jobs or destroy them at no cost. A new value of productivity is drawn when the conversion takes place.

There are two constraints to destroy permanent jobs. First, there are red-tape firing costs $f$, to be directly interpreted as the EPL gap under the previous assumption that termination of temporary contracts entail no red-tape firing costs. Secondly, time is needed to destroy permanent jobs: when an employer wishes to destroy this type of jobs, there

\footnotetext{
${ }^{19}$ We introduce an aggregate shock, which corresponds to the Great Recession, rather than a sequence of shocks as in L'Haridon and Malherbet (2009), Costain et al. (2010), or Sala et al. (2010).

${ }^{20}$ This assumption reduces the number of productivity cutoff levels to just two (see equation PJD and PJC below) which simplifies considerably the analysis and calibration of the model, without qualitatively affecting its main implications.
} 
is a firing permission which arrives at a Poisson rate $\sigma$ (Garibaldi, 1998). This firing permission typically captures not only advance notice, but also the uncertain time needed to settle legal disputes. Between the date at which the employer decides to destroy the job and the date at which the authorization arrives, we assume that the productivity of the job is lowest possible, i.e., equal to $\underline{\varepsilon}$, and that the interim wage equals the average wage in the economy, $\bar{\omega}$ (see the definition below) capturing in this fashion a prototypical employment record in this economy.

Unemployment benefits are denoted by $b$. Note that both firing costs and unemployment benefits should be interpreted as monetary flows in terms of the average wage, i.e., as $f \bar{\omega}$ and $b \bar{\omega}$, though for short they will be respectively referred to as $f$ and $b$ hereafter.

There is a Cobb-Douglas matching function $m(u, v)=m_{0} u^{\alpha} v^{1-\alpha}$ à la Pissarides (2000), with matching rates $q(\theta)$ for vacancies and $\theta q(\theta)$ for the unemployed. Thus, labor market tightness is given by $\theta=v / u$, where $v$ and $u$ are the masses of vacancies and unemployment, respectively. The degree of mismatch is captured by the shifter $m_{0}$ such that a lower value of $m_{0}$ signifies higher mismatch, that is, an outward shift in the Beveridge curve. Finally, there is a flow cost of keeping jobs vacant equal to $h>0$ per unit of time.

In terms of notation, subindices are as follows: $t$ stands for a temporary job, 0 for the beginning of a permanent job, $p$ for a continuing permanent job, and $a$ for jobs that wait for the authorization to be destroyed.

Asset values at steady state are denoted $J$ and $V$ for employers, and $W$ and $U$ for employees. They are as follows:

- $V$ : Value to the firm of a vacant job,

- $J_{t}(\varepsilon)$ : Value to the firm of a temporary job with productivity $\varepsilon$,

- $J_{0}(\varepsilon)$ : Value to the firm of a new permanent job with productivity $\varepsilon$, not yet subject to firing costs,

- $J_{p}(\varepsilon)$ : Value to the firm of a continuing permanent job with productivity $\varepsilon$, subject to both firing cost $f$ and advance notice 
- $J_{a}$ : Value to the firm of a permanent job under advance notice,

- $U$ : Value to the worker of unemployment,

- $W_{t}(\varepsilon)$ : Value to the worker of a temporary job with productivity parameter $\varepsilon$,

- $W_{0}(\varepsilon)$ : Value to the worker of a new permanent with productivity $\varepsilon$ subject to firing costs $f$ (recall that a new permanent job can previously be a temporary job),

- $W_{p}(\varepsilon)$ : Value to the worker of a continuing permanent job with productivity parameter $\varepsilon$, subject to firing costs $f$.

- $W_{a}$ : Value to the worker of a permanent job under advance notice.

\subsection{Bellman equations}

The Bellman equations for the firm's asset values are as follows:

$$
\begin{gathered}
r V=-h+q(\theta)\left[p\left(J_{t}(\bar{\varepsilon})-V\right)+(1-p)\left(J_{0}(\bar{\varepsilon})-V\right)\right] \\
r J_{t}(\varepsilon)=\varepsilon-w_{t}+\mu \int_{\underline{\varepsilon}}^{\bar{\varepsilon}}\left[J_{t}(x)-J_{t}(\varepsilon)\right] \mathrm{d} F(x)+\lambda \int_{\underline{\varepsilon}}^{\bar{\varepsilon}} \max \left[J_{0}(x)-J_{t}(\varepsilon), V-J_{t}(\varepsilon)\right] \mathrm{d} F(x) \\
r J_{0}(\varepsilon)=\varepsilon-w_{0}(\varepsilon)+\mu \int_{\underline{\varepsilon}}^{\bar{\varepsilon}} \max \left[J_{p}(x)-J_{0}(\varepsilon), J_{a}-J_{0}(\varepsilon)\right] \mathrm{d} F(x) \\
r J_{p}(\varepsilon)=\varepsilon-w_{p}(\varepsilon)+\mu \int_{\underline{\varepsilon}}^{\bar{\varepsilon}} \max \left[J_{p}(x)-J_{p}(\varepsilon), J_{a}-J_{p}(\varepsilon)\right] \mathrm{d} F(x) \\
r J_{a}=\underline{\varepsilon}-\bar{\omega}-\sigma\left[f+J_{a}-V\right]
\end{gathered}
$$

According to (1), keeping a vacant job implies a flow cost of $h$ and returns a contact with probability $q(\theta)$ in each period. Once the contact takes place, the employer-employee pair sign a temporary contract with probability $p$ or a new permanent contract with probability $1-p$, both created at the maximal productivity level, $\bar{\varepsilon}$. If a temporary contract is signed, equation (2) implies that the employer obtains a flow profit of $\varepsilon-w_{t}$, where $w_{t}$ is the pre-established wage for this type of contracts which does not depend on productivity. After the productivity shock takes place, at rate $\mu$, this type of job 
-which yields an asset value to the employer of $J_{t}(\varepsilon)$ - necessarily continues until the arrival of the date at which it can be destroyed. This assumption reflects the fact that employers are not allowed to layoff workers on temporary contracts before the end of the contract. Temporary contracts are terminated at rate $\lambda .^{21}$ When a temporary contract is terminated, the job can be either destroyed or converted into a permanent job. At the date of the termination of the temporary contract, a new value of the productivity shock is drawn in line with available evidence pointing out that workers' productivity may be different under permanent and temporary contracts. ${ }^{22}$

The asset value to the employer of a new permanent job, filled either by an unemployed worker or by a worker on a temporary contract, is $J_{0}(\varepsilon)$ which, according to (3), yields a flow profit of $\varepsilon-w_{0}(\varepsilon)$. Once a productivity shock occurs at rate $\mu$, the permanent contract becomes a continuing one -with an asset value to the firm of $J_{p}(\varepsilon)$-if the employer decides to keep the job, or it becomes a job under advance notice -with an asset value of $J_{a}$, if the employer prefers to fire the worker. Equation (4) indicates that the employer with a continuing job obtains a flow profit of $\varepsilon-w_{p}(\varepsilon)$, such that the only difference with the value of a new job -defined by equation (3)- is that the worker can now use both the firing cost and the advance notice, $J_{a}$, as additional threats in the wage bargain. As mentioned earlier, it is assumed that jobs under advance notice, whose value is defined by equation (5), have the lowest possible productivity $\underline{\varepsilon}$ and pay workers the average wage. These assumptions are a simple way to account for the fact that workers under advance notice generally provide low work effort and are paid a wage that depends on their past remuneration. Lastly, (5) also indicates that jobs under advance notice can be destroyed at an incidence rate $\sigma$.

Turning now to workers, their corresponding Bellman equations are given by:

$$
r U=b+\theta q(\theta)\left[p\left(W_{t}(\bar{\varepsilon})-U\right)+(1-p)\left(W_{0}(\bar{\varepsilon})-U\right)\right]
$$

\footnotetext{
${ }^{21}$ Assuming that the duration of temporary contracts is fixed rather than random leads to more complex formulations without changing the properties of the model.

${ }^{22}$ For example, Ichino and Riphahn (2005) have shown that the number of days of absence per week increases significantly once employment protection is granted at the end of probation periods.
} 


$$
\begin{gathered}
r W_{t}(\varepsilon)=w_{t}+\mu \int_{\underline{\varepsilon}}^{\bar{\varepsilon}}\left[W_{t}(x)-W_{t}(\varepsilon)\right] \mathrm{d} F(x)+\lambda \int_{\underline{\varepsilon}}^{\bar{\varepsilon}} \max \left[W_{0}(x)-W_{t}(\varepsilon), U-W_{t}(\varepsilon)\right] \mathrm{d} F(x) \\
r W_{0}(\varepsilon)=w_{0}(\varepsilon)+\mu \int_{\underline{\varepsilon}}^{\bar{\varepsilon}} \max \left[W_{p}(x)-W_{0}(\varepsilon), W_{a}-W_{0}(\varepsilon)\right] \mathrm{d} F(x) \\
r W_{p}(\varepsilon)=w_{p}(\varepsilon)+\mu \int_{\underline{\varepsilon}}^{\bar{\varepsilon}} \max \left[W_{p}(x)-W_{p}(\varepsilon), W_{a}-W_{p}(\varepsilon)\right] \mathrm{d} F(x) \\
r W_{a}=\bar{\omega}+\sigma\left[U-W_{a}\right]
\end{gathered}
$$

Equation (6) shows that an unemployed worker enjoys a flow earning $b$ and gets in contact with a vacancy at rate $\theta q(\theta)$, either of a temporary job or of a new permanent job, with probabilities $p$ and $1-p$, respectively. Expressions (7) to (9) represent the asset values to the worker of the different jobs, and their interpretation is similar to those in (2) to (4) with the flow income being the respective wages. Finally, (10) represents the asset value to the worker of being dismissed from a non-temporary job.

\subsection{Surplus sharing}

As is conventional in this type of models, the surplus is shared according to a Nash bargain in which workers have bargaining power $\beta \in[0,1]$. This gives rise to the surplus expressions:

$$
\begin{gathered}
S_{t}(\bar{\varepsilon})=J_{t}(\bar{\varepsilon})-V+W_{t}(\bar{\varepsilon})-U \\
S_{0}(\varepsilon)=J_{0}(\varepsilon)-V+W_{0}(\varepsilon)-U \\
S_{p}(\varepsilon)=J_{p}(\varepsilon)-J_{a}+W_{p}(\varepsilon)-W_{a}
\end{gathered}
$$

where the surplus for temporary jobs is defined at it initial productivity level, $\bar{\varepsilon}$, and those of permanent jobs at the date where the new productivity shock $\varepsilon$ arrives.

Since we have

$$
W_{a}+J_{a}=\frac{\underline{\varepsilon}+\sigma(U-f+V)}{r+\sigma}
$$

the surplus of continuing permanent jobs can be rewritten as

$$
S_{p}(\varepsilon)=J_{p}(\varepsilon)-V+f+W_{p}(\varepsilon)-U-\left(\frac{\varepsilon-r(U-f-V)}{r+\sigma}\right)
$$


The free-entry rule $V=0$ implies:

$$
h=q(\theta)\left[p J_{t}(\bar{\varepsilon})+(1-p) J_{0}(\bar{\varepsilon})\right]
$$

Therefore, since $J_{i}(\bar{\varepsilon})=(1-\beta) S_{i}(\bar{\varepsilon}), i=t, 0$, we get:

$$
\frac{\theta h}{1-\beta}=\theta q(\theta)\left[p S_{t}(\bar{\varepsilon})+(1-p) S_{0}(\bar{\varepsilon})\right]
$$

Bargaining, together with free entry, implies:

$$
\begin{aligned}
W_{0}(\varepsilon)-U & =\beta S_{0}(\varepsilon) \\
J_{0}(\varepsilon) & =(1-\beta) S_{0}(\varepsilon) \\
W_{p}(\varepsilon)-W_{a}(w) & =\beta S_{p}(\varepsilon) \\
J_{p}(\varepsilon)-J_{a}(w) & =(1-\beta) S_{p}(\varepsilon)
\end{aligned}
$$

From (12) and (13):

$$
S_{p}(\varepsilon)=S_{0}(\varepsilon)+\frac{1}{r+\sigma}\left(\sigma f+b+\theta \frac{\beta h}{1-\beta}-\underline{\varepsilon}\right)
$$

where $r U+\sigma f-\underline{\varepsilon}=b+\theta \frac{\beta h}{1-\beta}+\sigma f-\underline{\varepsilon}>0$ to ensure job destruction. Thus, the surplus from a continuing permanent job is larger than the surplus from a new permanent job, due to our previous assumption that the employer only has to pay the firing cost and to comply with the advance notice if the worker has been confirmed in the job and not when disagreement arises at the time of the first encounter with the worker.

\subsection{Job creation and job destruction}

The previous expressions for the surpluses yield the productivity thresholds used by firms for the destruction of permanent jobs (PJD) and the creation of permanent jobs (PJC): ${ }^{23}$

$$
\begin{gathered}
S_{p}\left(\varepsilon^{d}\right)=0=\varepsilon^{d}-\frac{r}{r+\sigma}(\underline{\varepsilon}-\sigma f)-\frac{\sigma}{r+\sigma}\left(b+\theta \frac{\beta h}{1-\beta}\right)+\mu \int_{\varepsilon^{d}}^{\bar{\varepsilon}} S_{p}(x) \mathrm{d} F(x) \\
S_{0}\left(\varepsilon^{c}\right)=0=\varepsilon^{c}+\frac{\mu}{r+\sigma}(\underline{\varepsilon}-\sigma f)-\frac{r+\sigma+\mu}{r+\sigma}\left(b+\theta \frac{\beta h}{1-\beta}\right)+\mu \int_{\varepsilon^{d}}^{\bar{\varepsilon}} S_{p}(x) \mathrm{d} F(x)
\end{gathered}
$$

\footnotetext{
${ }^{23}$ Notice that the job creation threshold does not exist for jobs filled by unemployed workers, since these jobs are created at the maximal productivity.
} 
Hence, subtracting (PJD) from (PJC) yields:

$$
\varepsilon^{c}=\varepsilon^{d}+\frac{r+\mu}{r+\sigma}\left(\sigma f+b+\theta \frac{\beta h}{1-\beta}-\underline{\varepsilon}\right)
$$

which shows that temporary jobs are destroyed more frequently than continuing permanent jobs, because they are exempt from firing costs. Moreover, the wedge between $\varepsilon^{c}$ and $\varepsilon^{d}$ increases with $f$ and $\sigma$.

From the expressions for $S_{p}(\varepsilon), S_{0}(\varepsilon), S_{p}\left(\varepsilon^{d}\right)$, and $S_{0}\left(\varepsilon^{c}\right)$, we get the following relations:

$$
\begin{aligned}
& S_{0}(\varepsilon)=\frac{\varepsilon-\varepsilon^{c}}{\mu+r} \quad \text { for } \varepsilon \geq \varepsilon^{c} \\
& S_{p}(\varepsilon)=\frac{\varepsilon-\varepsilon^{d}}{\mu+r} \quad \text { for } \quad \varepsilon \geq \varepsilon^{d}
\end{aligned}
$$

where (18) and (19) can be replaced into (PJD) to derive the following productivity threshold for the destruction rule of permanent jobs:

$$
\varepsilon^{d}=\frac{r}{r+\sigma}(\underline{\varepsilon}-\sigma f)+\frac{\sigma}{r+\sigma}\left(b+\theta \frac{\beta h}{1-\beta}\right)-\frac{\mu}{\mu+r} \int_{\varepsilon^{d}}^{\bar{\varepsilon}}\left(x-\varepsilon^{d}\right) \mathrm{d} F(x)
$$

This equation shows that the threshold productivity $\varepsilon^{d}$ is an increasing function of labor market tightness, $\theta$, and a decreasing function of the firing cost, $f .{ }^{24}$ The intuition for the first relationship is that a tighter labor market, by improving the value of unemployment $U$, reduces the surplus, thus making the employer-worker pair more exacting on how productive the match must be to compensate them for their outside options. As regards the second relationship, it is consistent with the goal of firing costs of reducing the propensity to destroy jobs, implying that less productive jobs remain operative.

Moreover, (11) implies that

$$
(r+\lambda) \int_{\underline{\varepsilon}}^{\bar{\varepsilon}} S_{t}(x) \mathrm{d} F(x)=\int_{\underline{\varepsilon}}^{\bar{\varepsilon}} x \mathrm{~d} F(x)-b-\frac{\beta \theta h}{1-\beta}+\lambda \int_{\varepsilon^{c}}^{\bar{\varepsilon}} \frac{\varepsilon-\varepsilon^{c}}{\mu+r} \mathrm{~d} F(x)
$$

and then,

$$
S_{t}(\varepsilon)=\frac{1}{(r+\mu+\lambda)}\left[\varepsilon+\frac{\mu}{r+\lambda} \int_{\underline{\varepsilon}}^{\bar{\varepsilon}} x \mathrm{~d} F(x)\right]+\frac{1}{r+\lambda}\left[\lambda \int_{\varepsilon^{c}}^{\bar{\varepsilon}} \frac{x-\varepsilon^{c}}{\mu+r} \mathrm{~d} F(x)-b-\frac{\beta \theta h}{1-\beta}\right]
$$

\footnotetext{
${ }^{24}$ It can be also shown to be an increasing function of the average duration of the advance notice period $(1 / \sigma)$, for values of $f$ sufficiently large, $\operatorname{since} \operatorname{sign}\left(\partial \varepsilon^{d} / \partial \sigma\right)=\operatorname{sign}(r U-\underline{\varepsilon}-r f)$. The intuition for this result is that, since the firm anticipates more firing restrictions when conditions are bad, it becomes more exacting (higher $\varepsilon^{d}$ ) as advance notice increases (as $\sigma$ falls).
} 
Evaluation of both $(21)$ and (18) at $\bar{\varepsilon}$ yields $S_{t}(\bar{\varepsilon})$ and $S_{0}(\bar{\varepsilon})$, respectively, which can be then used to rewrite the overall job creation equation (JC) out of the free-entry rule as follows:

$$
\frac{h}{1-\beta}=q(\theta)\left[\begin{array}{c}
\frac{p}{(r+\mu+\lambda)}\left[\bar{\varepsilon}+\frac{\mu}{r+\lambda} \int_{\underline{\varepsilon}}^{\bar{\varepsilon}} x \mathrm{~d} F(x)\right]+\frac{p}{r+\lambda}\left[\lambda \int_{\varepsilon^{c}}^{\bar{\varepsilon}} \frac{\left(x-\varepsilon^{c}\right)}{\mu+r} \mathrm{~d} F(x)-b-\frac{\beta \theta h}{1-\beta}\right] \\
+(1-p) \frac{\bar{\varepsilon}-\varepsilon^{c}}{\mu+r}
\end{array}\right]
$$

By replacing $\varepsilon^{c}$ by $\varepsilon^{d}$ in equation (JC), using equation (17), it is easy to show that, along the JC locus, labor tightness $\theta$ is a decreasing function of the job destruction productivity cutoff $\varepsilon^{d}$. In other words, the lower the destruction threshold $\varepsilon^{d}$, the longer jobs last on average, which leads to a higher creation of vacancies. Conversely, for a given value of $\varepsilon^{d}$, a higher firing cost $f$ reduces the expected present value of jobs and therefore hinders job creation.

In sum, besides the unemployment rate (see below), the steady-state equilibrium values of the other three unknowns in our model, $\theta, \varepsilon^{c}$, and $\varepsilon^{d}$, are found by solving the system of equations given by (JC), (17) and (20). Equilibrium is depicted in Figure 3, where the crossing of the JC (having replaced $\varepsilon^{c}$ by $\left.\varepsilon^{d}\right)$ and PJD loci in the $\left(\theta, \varepsilon^{d}\right)$ space determines the equilibrium values of these two variables, whereas (17) determines the equilibrium value of $\varepsilon^{c}$. In Figure 4 we consider the effect of an increase in the firing cost gap between permanent and temporary workers. This is captured by a rise in $f$, which shifts the PJD and JC schedules downwards and the PJC locus upwards. ${ }^{25}$ Firms unambiguously fire less permanent workers (lower $\varepsilon^{d}$ ), transform temporary contracts into permanent ones less frequently (higher $\varepsilon^{c}$ ), and reduce labor market tightness $(\theta)$ for given values of the productivity thresholds. Although in principle the conventional ambiguity on the effect of firing costs on unemployment holds, as a result of the lower job creation and destruction rates, it will be shown below that, in a dual labor market which initially exhibits a high gap in firing costs, a further increase in $f$ will raise unemployment. The intuition is that, if the conversion rate from temporary to permanent contracts is low to start with, a further rise in $f$ exacerbates temporary workers' turnover precisely when less vacancies are being

\footnotetext{
${ }^{25}>$ From equations (17) and (20), we get $\left.\frac{\mathrm{d} \varepsilon^{c}}{\mathrm{~d} f}\right|_{\theta=\operatorname{ctant}}=\frac{\mu F\left(\varepsilon^{d}\right)}{1-\frac{\mu}{\mu+r}\left[1-F\left(\varepsilon^{d}\right)\right]}>0$.
} 
created. Thus, unemployment is likely to go up, as Blanchard and Landier (2002), and Cahuc and Postel-Vinay (2002) have pointed out before.

Figure 5, in turn, shows the effect of a reduction in $p$, an EPL policy parameter which, as mentioned earlier, is bound to be higher in Spain than in France because the laxer restrictions in the use of temporary contracts and the higher weight of the construction sector in Spain before the current recession. Now, the PJC and PJD loci remain unaffected whereas the JC schedule shifts downwards, since job creation is hindered by the lower availability of flexible contracts. As a result, the equilibrium value of $\theta$ unambiguously decreases whereas the two productivity cutoff values fall. In other words, since decreasing $p$ lowers job creation, firms become less exacting about hiring and firing, making job turnover less intensive. As a result, despite the fall in $\theta$, the impact of a reduction of $p$ on the unemployment rate is ambiguous. However, like before, if the economy has a large firing costs to start with, a reduction in $p$ is likely to decrease temporary workers' turnover, and this may reduce unemployment, as our quantitative simulations below show. Finally, it is straightforward to check that either a rise in $\lambda$ (i.e. a higher frequency in the termination of temporary jobs) or a reduction in $m_{0}$ (i.e. an increase in mismatch) unambiguously lead to lower $\theta$ and higher unemployment.

\subsection{Unemployment flows}

Let us denote by $N_{t}$ the number of workers with a temporary contract, $N_{p}$ those with a permanent contract not subject to advance notice, $N_{a}$ those with a permanent contract subject to advance notice, and $u$ the number of unemployed workers. Then we have:

$$
\begin{aligned}
\dot{N}_{t} & =p u \theta q(\theta)-\lambda N_{t} \\
\dot{N}_{p} & =(1-p) u \theta q(\theta)+\lambda N_{t}\left[1-F\left(\varepsilon^{c}\right)\right]-\mu N_{p} F\left(\varepsilon^{d}\right) \\
\dot{N}_{a} & =\mu N_{p} F\left(\varepsilon^{d}\right)-\sigma N_{a} \\
\dot{u} & =\lambda F\left(\varepsilon^{c}\right) N_{t}+\sigma N_{a}-u \theta q(\theta)
\end{aligned}
$$

In steady state, the number of workers in the different type of jobs and the unemploy- 
ment rate, $u^{*}$, become:

$$
\begin{gathered}
N_{t}^{*}=\frac{1}{\lambda} p u^{*} \theta q(\theta) \\
N_{p}^{*}=\theta u^{*} q(\theta) \frac{1-p F\left(\varepsilon^{c}\right)}{\mu F\left(\varepsilon^{d}\right)} \\
N_{a}^{*}=\frac{u^{*} \theta q(\theta)}{\sigma}\left[1-p F\left(\varepsilon^{c}\right)\right] \\
N_{a}^{*}+N_{p}^{*}=\frac{u^{*} \theta q(\theta)}{\mu F\left(\varepsilon^{d}\right)}\left[1-p F\left(\varepsilon^{c}\right)\right] \frac{\sigma+\mu F\left(\varepsilon^{d}\right)}{\sigma} \\
u^{*}=1-N_{p}^{*}-N_{a}^{*}-N_{t}^{*}
\end{gathered}
$$

Solving (23), (25) and (26) for the unemployment rate in steady state, yields:

$$
u^{*}=\frac{\lambda \sigma \mu F\left(\varepsilon^{d}\right)}{\lambda \sigma \mu F\left(\varepsilon^{d}\right)+\theta q(\theta)\left[\sigma \mu p F\left(\varepsilon^{d}\right)+\lambda\left[1-p F\left(\varepsilon^{c}\right)\right]\left[\sigma+\mu F\left(\varepsilon^{d}\right)\right]\right.}
$$

This equation will serve us to illustrate the result that economies in which the EPL gap is too large, unemployment will be higher than in those where the gap is smaller. For that, first notice that $u^{*}$ increases ceteris paribus with the cutoff productivity levels $\varepsilon^{d}$ and $\varepsilon^{c}$. Moreover, since according to (20) the direct effect of a higher gap $f$ is to increase the wedge $\varepsilon^{c}-\varepsilon^{d}$, the higher is $f$ the more likely it is that $F\left(\varepsilon^{c}\right) \gg F\left(\varepsilon^{d}\right)$. Then, by continuity, this argument implies the existence of a threshold value of the gap in firing costs, $\bar{f}$, such that, for $f>\bar{f}, u^{*}$ will increase with $f$. Heuristically, the insight for this result is that, if the initial value of $f$ is sufficiently large, $F\left(\varepsilon^{c}\right)$ will become the dominant term when differentiating (27) with respect to $f .{ }^{26}$ Regarding the effect of a reduction in the proportion of temporary jobs $p$ on unemployment, it is ambiguous as reflected by the two counteracting terms in the denominator of (27) associated to $p: \sigma \mu F\left(\varepsilon^{d}\right)$, on the one hand, and $-\lambda F\left(\varepsilon^{c}\right)\left[\sigma+\mu F\left(\varepsilon^{d}\right)\right]$, on the other. However, using the same argument as before, when $f$ is sufficiently large, $F\left(\varepsilon^{c}\right)$ will dominate $F\left(\varepsilon^{d}\right)$ in the differentiation of (27) with respect to $p$, so that a reduction in $p$ lowers unemployment. The intuition this time is that a lower $p$ means restricting the use of temporary jobs which, in a economy with large $f$, are destroyed more frequently than permanent jobs.

\footnotetext{
${ }^{26}$ The exact value of $\bar{f}$ depends on the other parameter values in a rather cumbersome way but the intuition given above remains valid.
} 


\subsection{Wages}

As mentioned earlier, wages are set according to a Nash bargain in which workers have bargaining power $\beta \in[0,1]$. While they can be renegotiated on permanent jobs, we assume that this is not the case for temporary jobs where the wage $w_{t}$ is taken to be invariant throughout the length of the contract. Nash bargaining yields:

$$
\begin{aligned}
(1-\beta)\left[W_{t}(\bar{\varepsilon})-U\right] & =\beta\left[J_{t}(\bar{\varepsilon})-V\right] \\
(1-\beta)\left[W_{0}(\varepsilon)-U\right] & =\beta\left[\left(J_{0}(\varepsilon)-V\right]\right. \\
(1-\beta)\left[W_{p}(\varepsilon)-W_{a}\right] & =\beta\left[\left(J_{p}(\varepsilon)-J_{a}\right]\right.
\end{aligned}
$$

Using (2)-(4) and (7)-(9), $r U=b+\theta \frac{h \beta}{1-\beta}, J_{a}=\frac{\varepsilon-\bar{\omega}-\sigma f}{r+\sigma}$, and $W_{a}=\frac{\bar{\omega}+\sigma U}{r+\sigma}$, we get the following expressions for the wages:

$$
\begin{gathered}
w_{t}=\beta \bar{\varepsilon}+(1-\beta) r U \\
w_{0}(\varepsilon)=\beta\left(\varepsilon+\frac{r+\mu+\sigma}{r+\sigma} \theta h-\frac{\sigma}{r+\sigma} \mu f\right)+\frac{\mu}{r+\sigma}(\beta \underline{\varepsilon}-\bar{\omega})+\frac{r+\mu+\sigma}{r+\sigma}(1-\beta) b \\
w_{p}(\varepsilon)=\beta\left(\varepsilon+\frac{\sigma}{r+\sigma} \theta h+\frac{\sigma}{r+\sigma} r f\right)-\frac{r}{r+\sigma}(\beta \underline{\varepsilon}-\bar{\omega})+\frac{\sigma}{r+\sigma}(1-\beta) b
\end{gathered}
$$

It can be easily checked that $w_{0}(\varepsilon)<w_{p}(\varepsilon)$ and $w_{0}(\varepsilon)<w_{t}$. Notice that, when $\sigma \rightarrow \infty$ (i.e. no advance notice), $w_{p}(\varepsilon)=w_{t}+\beta[r f-(\bar{\varepsilon}-\varepsilon)]$, so that the wage of permanent workers is not necessarily larger than the wage of temporary workers because the latter always start at the highest productivity level. Nonetheless, the larger is $f$ the more likely it is that $w_{p}(\varepsilon)>w_{t}$. Similar qualitative results hold when $\sigma$ is finite.

Finally, to compute the average wage in steady state, $\bar{\omega}$, let us denote by $N_{0}$ the number of temporary jobs that have just been created with productivity $\bar{\varepsilon}$ and that have not yet been hit by a productivity shock since their creation, and by $N_{0 t}$ the corresponding number of permanent jobs that have not been hit by a shock since they were transformed from temporary jobs. Then:

$$
\begin{aligned}
\dot{N}_{0} & =(1-p) u \theta q(\theta)-\mu N_{0} \\
\dot{N}_{0 t} & =\lambda N_{t} p\left[1-F\left(\varepsilon^{c}\right)\right]-\mu N_{0 t}
\end{aligned}
$$


such that their steady-state values become:

$$
\begin{aligned}
N_{0} & =\frac{(1-p) u \theta q(\theta)}{\mu} \\
N_{0 t} & =\frac{p u \theta q(\theta)\left[1-F\left(\varepsilon^{c}\right)\right]}{\mu}
\end{aligned}
$$

Using the previous employment sizes, it follows that the weighted average wage in this economy becomes:

$$
\bar{\omega}=\frac{N_{t} w_{t}+\frac{N_{0 t}}{1-F\left(\varepsilon^{c}\right)} \int_{\varepsilon^{c}}^{\bar{\varepsilon}} w_{0}(x) \mathrm{d} F(x)+N_{0} w_{0}(\bar{\varepsilon})+\frac{\left(N_{p}-N_{0 t}-N_{0}\right)}{1-F\left(\varepsilon^{d}\right)} \int_{\varepsilon^{d}}^{\bar{\varepsilon}} w_{p}(x) \mathrm{d} F(x)}{1-u-N_{a}}
$$

For example, assuming that $F($.$) is the c.d.f. of a uniform distribution U[\underline{\varepsilon}, \bar{\varepsilon}]$ and that there is no advance notice, $\bar{\omega}$ is given by:

$$
\bar{\omega}=\frac{\beta h \theta(1-u)+\beta \bar{\varepsilon}\left(N_{t}+N_{0}\right)+\beta \frac{\bar{\varepsilon}+\varepsilon^{c}}{2} N_{o t}+\beta \frac{\bar{\varepsilon}+\varepsilon^{d}}{2}\left(N_{p}-N_{0}-N_{0 t}\right)}{(1-u)(1-b(1-\beta))+f(\mu+r)\left(N_{0}+N_{o t}\right)-f r N_{p}}
$$

\section{Accounting for the impact of the crisis}

In this section, we first show how we calibrate a number of key parameters in the model and then discuss the results of a simulation exercise where we try to ascertain the extent to which the difference in EPL regulation between Spain and France can account for the strikingly different evolution of their respective unemployment rates during the crisis.

\subsection{Calibration of the model}

The length of a model period is chosen to be one quarter. Some of the values of the model's parameters can be imputed directly from data, but others need to be endogenously calibrated to fit a set of labor market magnitudes. Our reference period for the calibration is the latter part of the boom preceding the recession, namely 2005:1-2007:4. The reason is that the unemployment rates in both countries were similar at that time and our goal is precisely to let the model explain the unemployment rate in the bad state (after the crisis) relative to the good state (before the crisis).

Parameter values are presented in Table 2. The interest rate $r$ is set at $1 \%$ per quarter. As in most of the literature (see, e.g., Petrongolo and Pissarides, 2001), we set the value 
for both the elasticity of the matching function with respect to unemployment $(\alpha)$ and bargaining power $(\beta)$ equal to 0.5 .

As for the unemployment benefit indicator $b$, we use statutory replacement rates corrected for benefit coverage, setting it to $55 \%$ for France and $58 \%$ for Spain. Indicators $f, \sigma$, and $p$ are chosen to represent each country's EPL. As regards $f$, recall that it reflects red-tape firing costs. Kramarz and Michaud (2010) calculate the average firing cost for permanent workers in France to be around one year's wages, with red-tape costs accounting for one third of this amount (i.e. 1.33 quarters). For Spain, we compute it as the (weighted) difference between actually paid severance (45 days of wages per year of service, in either individual or collective dismissals), which is induced by labor courts and authorities, and statutory severance for dismissals based on economic reasons (20 days). Making use of observed employment tenures yields a value of 2 quarters. Thus, the value of $f$ for Spain is $50 \%$ higher than in France. In contrast, the average advance notice period $(1 / \sigma)$ is longer in France, where it is set to last four months $(\sigma=0.75)$, than in Spain, where it is set at 3 weeks $(\sigma=4.3) .{ }^{27}$

Parameter $p$, which represents the proportion of newly created contracts that are temporary, is set to 0.85 in France and 0.91 in Spain in the boom. As already indicated, one of the main reasons for the larger value of $p$ in Spain is the much higher weight of employment in the construction industry during the reference period which, as argued before, has been an important source of hiring of temporary workers in this country. Parameter $\lambda$, which captures the (inverse of) the duration of temporary contracts, is set equal to 0.88 both in France and Spain before the crisis, in line with the information drawn from their Labor Force Survey (LFS). ${ }^{28}$

To simplify computations, the idiosyncratic productivity shock is assumed to be uniformly distributed, with $\underline{\varepsilon}=0$ and $\bar{\varepsilon}=1$. Finally, to uncover the values of the remaining

\footnotetext{
${ }^{27}$ In France, the advance notice period is 2 months but it increases to 3 months in many collective agreements and above 6 months for collective layoffs. Further, the fact that employers ought to interview the worker often implies that it takes around one more month before the employer can send the letter letting the worker know that he/she is fired. In Spain, Law 45/2002, discussed in Section 3.1, has reduced substantially the advance notice period since 2002 .

${ }^{28}$ For Spain we also use Social Security data, namely the Muestra Continua de Vidas Laborales (MCVL).
} 
three parameters $\left(h, m_{0}\right.$, and $\left.\mu\right)$, for which no direct information is available, we calibrate them to match the outcomes of the following three equations defining key labor market variables (targets) related to temporary and permanent employment jobs and the overall unemployment rate in each economy, which are computed using the French and Spanish LFS. The first equation refers to the destruction rate of permanent jobs, which is defined (in steady state) by:

$$
\frac{\sigma N_{f}^{*}}{N_{p}^{*}+N_{a}^{*}}=\frac{\sigma \mu F\left(\varepsilon^{d}\right)}{\sigma+\mu F\left(\varepsilon^{d}\right)}
$$

Secondly, we use the share of temporary jobs in the total stock of jobs (in steady state), given by:

$$
\frac{N_{t}^{*}}{N_{t}^{*}+N_{p}^{*}+N_{a}^{*}}=\frac{p \sigma \mu F\left(\varepsilon^{d}\right)}{\lambda\left[\sigma+\mu F\left(\varepsilon^{d}\right)\right]\left[1-p F\left(\varepsilon^{c}\right)\right]+p \sigma \mu F\left(\varepsilon^{d}\right)}
$$

Lastly, we use the steady-state unemployment rate given in equation (27).

Once the model has been calibrated to reproduce the stylized facts during the reference period, we obtain simulations for the recession allowing for adverse changes in the productivity distribution and possibly in mismatch. These simulations are obtained for two specifications of the average wage $\bar{\omega}$ applied to compute the monetary flows of the firing cost and the unemployment benefit during the recession. In the first one we consider that $\bar{\omega}$ corresponds to the contemporaneous calibrated average wage (i.e. in the bad state). In the second specification $\bar{\omega}$ takes its previously calibrated value in the good state. This is meant to mimic the fact in reality unemployment benefits and severance pay are linked to workers' previous experience and tenure, respectively. For notational convenience, these two specifications will be labeled as the endogenous wage model and the fixed $f-b$ model respectively.

\subsection{Simulation results}

In this section we summarize the main results of several simulation exercises. We present targets (actual data) and outcomes (simulated data) for both countries in the expansionary and recessionary periods, using the two alternative ways of computing $\bar{\omega}$ just described. 
For the sake of brevity, however, we will mainly focus on the results stemming from the fixed $f-b$ model, which we see as a more realistic setup.

Table 3 presents the data (target values) and the steady-state value of the unemployment rate and temporary contract share during the expansion (based on data for 2005:1-2007:4) and the recession (2008:1-2009:4). ${ }^{29}$ As can be observed, for the reference expansionary period, for both countries we are able to match fairly well the chosen target variables, especially the unemployment and the temporary employment rates.

We follow two approaches in running the simulations for the recession. First, we consider a baseline simulation where the only degree of freedom in matching targets during the slump is a parameter controling the severity of the productivity shock through a shift in its distribution, whereas all other parameters in the model remain the same as in the preceding expansion. Specifically, we assume that the productivity distribution is shifted by a multiplicative factor $\gamma$, so that productivity is assumed to be uniformly distributed with support $\gamma[\underline{\varepsilon}, \bar{\varepsilon}]$ and $\gamma$ is calibrated to match the required three targets during the recession. Secondly, we compute an alternative simulation where, besides the severity of the shock, we allow for another model parameter to change, namely, $m_{0}$. This is meant to allow reallocation shocks to play a role in capturing, e.g., mismatch created by the collapse of the construction industry in Spain, so as to check if there is any improvement in the overall matching of the targets.

Table 3 (row 4), shows that the baseline simulation allows us to match fairly well the unemployment and temporary employment rates for France during the recession with a value of $\gamma$ equal to 0.90 , namely and adverse shift of $10 \%$ in average productivity. Notice, however, that this exercise makes sense only if the unemployment rate reaches its steady state value fast enough. Figure 6 shows that this is indeed the case: the speed of adjustment of the unemployment rate is high in France. Most of the adjustment to the new steady state after the negative shock at the origin of the recession is made in 6

\footnotetext{
${ }^{29}$ Given the trending behavior of the unemployment and the temporary employment rates, especially in Spain, in a few instances we have replaced the period average by a given data point which we see as more representative of the corresponding business cycle.phase.
} 
months $(25$ weeks $) .^{30}$

Table 3 (row 8), shows that the baseline simulation for Spain with $\gamma=0.77$-i.e. a much more adverse shock than in France- matches the value of the unemployment rate during the recession well but it fails badly in matching the share of temporary jobs, which has fallen from $33.3 \%$ to $27 \%$ whereas the simulation yields an increase to almost $38 \%$. Given this unsatisfactory result and the arguments posed in Section 3.4 about the likely increase in mismatch following the negative aggregate shock in Spain, we perform the alternative simulation where we allow for a newly calibrated value of $m_{0}$ together with a new $\gamma$. This calibration exercise yields an increase in the degree of mismatch, captured by a reduction of $m_{0}$ from its initial value of 2.5 to 1.5 and a similar value for $\gamma$ to that obtained for France, namely $\gamma=0.87$. Notice that the outward shift in the Beveridge curve illustrated in Figure 2 reflects reallocation distortions rather than aggregate shocks and hence the correct interpretation of the recession in Spain would be a combination of both types of shocks. In line with the discussion in Section 3.4, higher mismatch leads to a rise in unemployment through lower labor mobility driven both by the higher risk involved in the increasing destruction of temporary jobs and the rigid regulations affecting the Spanish rental market. In other words, workers who have lost their jobs in regions with high unemployment, because of the collapse of the construction industry, find it very costly to move to other regions where unemployment is lower. The results reported in the last row of Table 3 for this alternative scenario show a substantial improvement in matching the target on temporary work (27\% in the data vs. $27.9 \%$ in the simulation), while the much higher unemployment rate remains satisfactorily reproduced.

Figure 7 represents the transitional dynamics of the unemployment rate for Spain. As in France, it turns out that the speed of adjustment to the steady state is very fast. Accordingly, comparing steady states in the expansion and the recession allows us to

\footnotetext{
${ }^{30}$ The dynamics are easy to compute because the core of the model is forward looking. As soon as the economy is hit by an unfavorable shift in the distribution of productivity, the thresholds jump to their new stady-state values. We then essentially look at the adjustment of the stocks given the new flows, noting that some permanent workers will be laid off even without having been hit by an "idiosyncratic" shock because of the shift in the thresholds.
} 
account well for changes in the unemployment rates in both countries.

\subsubsection{Counterfactual simulations: Spain with French EPL regulations}

Once we have managed to get a calibration that behaves well in both the good and bad states, we can use this model to run counterfactual simulations aimed at gauging the share of the increase in unemployment induced by the recession in Spain that can be attributed to differences in its EPL vis-à-vis France's. In other words, we carry out this counterfactual simulation by computing what would have been the increase in unemployment during the Great Recession had Spain adopted French EPL just before the slump started. ${ }^{31}$

We interpret the adoption of French EPL in two ways, namely in a broad and in a narrow sense. First, it is interpreted as involving not only the direct effect on worker turnover of adopting a lower value of $f$ but also the related indirect effects of a reduction in $f$ on the use of temporary contracts. A lower $f$ is bound to lead to many more conversions as well as more direct hiring of workers under permanent contracts. Thus, under this broad interpretation, besides using the French value of $f$, we also impute to Spain the French share of hires on temporary jobs, $p$. This can also be interpreted as a tightening of the enforcement of the criteria for allowing the use of temporary contracts.

The results from these simulations are presented in Table 4. To compute the counterfactual rise in Spanish unemployment, we follow a difference-in-differences approach where we compare steady-state unemployment before and after the negative aggregate shock in France and in Spain. For instance, for the fixed $f-b$ model under the broad interpretation of EPL, the first row in panel A of Table 4 shows the result of subtracting from the overall change in unemployment, $7.43 \mathrm{pp}$., the change predicted had Spain had the French parameters, namely, $4.05 \mathrm{pp}$. The implication is that the recession would have raised the unemployment rate in Spain by 3.38 pp. less (i.e. about $45 \%$ of the actual increase) had Spain adopted French EPL rather than kept its own. The endogenous wage model provides a lower outcome of $1.42 \mathrm{pp}$. (about 20\% less unemployment than the

\footnotetext{
${ }^{31}$ Notice that this assumption about the timing of the adoption of French EPL in Spain implies that we do not need to re-calibrate the model in the good state.
} 
actual increase) revealing that higher wage flexibility reduces the adverse effects of the EPL gap and the corresponding widespread use of temporary contracts on unemployment. However, it is likely that the endogenous wage model overestimates downward wage flexibility since, according to the simulations for this case real wages fall by $0.2 \%$, while in reality they increased by $2.5 \%$ during the slump (see Table 1 ).

Regarding the dynamics, Figure 8 depicts three transition paths of the Spanish unemployment rate in the recession for the fixed $f-b$ model. Instead of depicting the unemployment rate in levels, we plot the deviations of the unemployment rate following the recession from the steady-state value in the good state, i.e. $u=10.2 \%$ (see the third panel in Table 3). The solid line corresponds to the simulation with Spanish parameters whereas the dashed line captures the case where the values of $f$ and $p$ are replaced by the French ones. As can be observed, the dynamics in the counterfactual scenario exhibit an overshooting of about $2 \mathrm{pp}$. in the short-run after the adverse productivity shock hits the economy. The reason is that a reduction in the EPL gap, concerning both firing costs and the use of temporary contracts, exacerbates job destruction in the short run during the recession by making layoffs less expensive. Specifically, an increase in the productivity cutoff for job destruction, $\varepsilon^{d}$, from 0.76 to 0.86 induces the overshooting. However, in the long run, this is offset by much higher job creation, so that unemployment goes down to a new steady state with the properties discussed above: i.e. about $3.4 \mathrm{pp}$. larger when Spain keeps its own EPL rather than having adopted the French one.

Next, panel B in Table 4 presents the results of the simulation under the narrow interpretation of French EPL adoption, i.e. Spanish unemployment with French layoff costs but the Spanish regulation of temporary jobs. The line with crosses of Figure 8 depicts the transitional dynamics of the unemployment rate in this case. The result of the counterfactual increase in Spanish unemployment, is quite smaller than before. This result stresses the importance of the regulation of fixed temporary jobs in combination with a reduction in the EPL gap, especially because, as stressed in Section 3.4, we believe that there should be a close link among changes in $f$ and in $p$. Endogeneizing $p$ as a 
function of $f$ is bound to be hard in this type of equilibrium search and matching models but it remains a relevant item in our research agenda.

Finally, panel $\mathrm{C}$ in Table 4 reports the results obtained in the converse simulation exercise, now addressing the question: By how much would French unemployment have risen during the recession had France adopted Spanish EPL? In line with our previous discussion, we use the broad interpretation of Spanish EPL in terms of the bundle of parameters $(f, p)$. The result is that, instead of the observed rise of $1.5 \mathrm{pp}$., the French unemployment rate would have risen by $3.1 \mathrm{pp}$., that is $1.9 \mathrm{pp}$. more than with their own regulations when the average wage $\bar{\omega}$ applied to $f$ and $b$ remains as in the good state, and by only $1.3 \mathrm{pp}$. under the endogenous wage model. Therefore, these result confirm the previous counterfactual findings for Spain that a higher $(f, p)$ combination induces a larger increase in unemployment to a given negative shock.

\section{Conclusions}

In this paper we explore how much of the significantly larger increase in unemployment in Spain vis-à-vis France during the ongoing recession can be accounted for the difference in EPL between the two countries. We have argued that the larger gap between the dismissal costs of workers with permanent and temporary contracts in Spain as compared to France has led to different labor mobility and industrial specialization, huge flows of temporary workers into and out of unemployment and, as a result, large job losses during the Great Recession.

To carry out this task, inspired by previous work by Blanchard and Landier (2002) and Cahuc and Postel-Vinay (2002), we have used a search and matching model that extends Mortensen-Pissarides (1994) to allow for the distinction between temporary and permanent jobs entailing different dismissal costs. After calibrating the parameters with data for the two economies, we simulate the model to replicate a few key labor market magnitudes for the expansion (2005-2007) and recession periods (2008-2009).

Subsequently we undertake several counterfactual exercises involving the key parame- 
ters capturing employment protection and industry composition in the model, which we interpret to be closely related. Imputing the French-economy levels of a couple of subsets of these parameters to the Spanish economy yields a robust result, namely that the current recession would have raised the unemployment rate in Spain by about $45 \%$ less than the observed rise (8 pp. on average between 2005-07 and 2008-2009) had Spain adopted French EPL institutions rather than kept its own. It is worth noting that this could be interpreted as a conservative estimate of the true effect since we have only considered the effect of red-tape firing costs in our exercise. Moreover, if wage rigidity were considered to be higher than that implied by standard Nash bargaining, then it is likely that the contribution of the overall gap in EPL to the surge in Spanish unemployment during the Great Recession could have been even larger.

Recently there have been several policy initiatives in Europe defending the idea of eliminating the firing cost gap through the introduction of a single labor contract. Among these proposals are those of Blanchard and Tirole (2003) and Cahuc and Kramarz (2004) for France, Boeri and Garibaldi (2008) and Ichino (2009) for Italy, and a manifesto signed by 100 academic economists, see Andrés et al. (2008), for Spain. While not identical in their details, all these proposals highlight the negative effects induced by the permanenttemporary contract divide. As a result, they all advocate the elimination of temporary contracts and the introduction of a single labor contract with severance pay that is increasing with seniority in the job. ${ }^{32}$ The results in this paper, by finding a rather sizable impact of the firing cost gap on the rise in unemployment during the crisis, provide some support for these proposals.

\footnotetext{
${ }^{32}$ For a specific proposal of a single contract for Spain and its consequences in terms of expected protection and job stability, see Garcia-Perez (2009).
} 


\section{Appendix}

Table A1. Employment protection legislation in France and Spain

\begin{tabular}{|c|c|c|}
\hline & Permanent contracts & Temporary contracts \\
\hline \multicolumn{3}{|l|}{ France } \\
\hline * Notice period & $\begin{array}{l}1 \text { month if } 6<\text { seniority (months) }<24 \\
2 \text { months if seniority (months) } 24\end{array}$ & \\
\hline \multicolumn{3}{|l|}{ * Severance pay } \\
\hline $\begin{array}{l}\text { 1. Economic } \\
\text { reasons }\end{array}$ & $\begin{array}{l}6 \text { days of wages pys. }(20 \% \text { of wage }) \\
+0.08 \text { days' wages pys. }>10 \text { yrs } \\
(1 / 15 \text { of monthly wage })\end{array}$ & 3 days of wages pys. \\
\hline 2. Personal & Minimum seniority: 1 year & \\
\hline $\begin{array}{l}\text { reasons } \\
\text { (before July 2008) }\end{array}$ & $\begin{array}{l}3 \text { days of wages pys. ( } 10 \% \text { of wage) } \\
+0.04 \text { days' wages pys. }>10 \text { yrs }\end{array}$ & \\
\hline Observations & $\begin{array}{l}\text { Personalized plan } \\
\text { for up to } 12 \text { months }\end{array}$ & $\begin{array}{l}\text { Max. duration: } 24 \text { months } \\
\text { Restricted to } 9 \text { cases } \\
\text { (see text) }\end{array}$ \\
\hline \multicolumn{3}{|l|}{ Spain } \\
\hline * Notice period & 1 month & \\
\hline \multicolumn{3}{|l|}{ * Severance pay } \\
\hline $\begin{array}{l}\text { 1. Economic } \\
\text { reasons }\end{array}$ & $\begin{array}{l}20 \text { days of wages pys. } \\
\text { Max. seniority coverage: } 12 \text { months }\end{array}$ & $\begin{array}{l}8 \text { days of wages pys. } \\
\text { ( } 0 \text { days in some cases, } \\
\text { see text) }\end{array}$ \\
\hline Observations & $\begin{array}{l}\text { Collective dismissal requires } \\
\text { administrative approval }\end{array}$ & $\begin{array}{l}\text { Max. duration: } 24 \text { months } \\
\text { Unrestricted }\end{array}$ \\
\hline $\begin{array}{l}\text { 2. Unfair } \\
\text { dismissal }\end{array}$ & $\begin{array}{l}45 \text { days of wages pys. } \\
\text { Max. seniority coverage: } 42 \text { months }\end{array}$ & \\
\hline
\end{tabular}

Note: "pys." means per year of service. 


\section{References}

[1] Andrés, J. et al. (2009), "Propuesta para la Reactivación Laboral en España" (2009), El Pais, 26 April ("A Proposal to Restart the Spanish Labor Market", crisis09.es/PDF/restart-the-labor-market.pdf).

[2] Antolín, P. and O. Bover (1997), "Regional Migration in Spain: The Effect of Personal Characteristics and of Unemployment, Wage and House Price Differentials using Pooled Cross-Sections", Oxford Bulletin of Economics and Statistics 59, 215-235.

[3] Barceló, C. (2006), "Housing Tenure and Labour Mobility: A Comparison across European Countries", Banco de España Working Paper 0603.

[4] Becker, S. O., S. Bentolila, A. Fernandes, and A. Ichino (2010), "Youth Emancipation and Perceived Job Insecurity of Parents and Children", Journal of Population Economics 23, 1047-1071.

[5] Bentolila, S. and J. J. Dolado (1991), "Mismatch and internal migration in Spain, 1962-1986", in F. Padoa Schioppa (ed.), Mismatch and labour mobility, Cambridge University Press, Cambridge.

[6] Bentolila, S., J. J. Dolado, and J. F. Jimeno (2008a), "Does Immigration affect the Phillips Curve? Some Evidence for Spain", European Economic Review 52, 13981423.

[7] Bentolila, S., J. J. Dolado, and J. F. Jimeno (2008b), "Two-tier Employment Protection Reforms: The Spanish Experience", CESifo DICE Report 4/2008.

[8] Bentolila, S. and A. Ichino (2008), "Unemployment and Consumption Near and Far Away from the Mediterranean", Journal of Population Economics 21, 255-280.

[9] Bentolila, S. and J. F. Jimeno (2006), "Spanish Unemployment: The End of the Wild Ride?", in M. Werding (ed.), Structural Unemployment in Western Europe. Reasons and Remedies, MIT Press, Cambridge, MA.

[10] Bentolila, S. and G. Saint-Paul (1992), "The Macroeconomic Impact of Flexible Labor Contracts, with an Application to Spain", European Economic Review 36, 1013-1047.

[11] Blanchard, O. J. and A. Landier (2002), "The Perverse Effects of Partial Labor Market Reform: Fixed Duration Contracts in France", Economic Journal 112, 214244. 
[12] Blanchard, O. J. and J. Tirole (2003), "Contours of Employment Protection Reform", MIT Department of Economics Working Paper 03-35.

[13] Boeri T. and P. Garibaldi P. (2007), "Two Tier Reforms of Employment Protection Legislation. A Honeymoon Effect?", Economic Journal 117, F357-F385.

[14] Boeri T. and P. Garibaldi P. (2008), Un Nuovo Contratto per Tutti, Chiarelettere, Torino.

[15] Bouvet, F. (2009), "The Beveridge Curve in Europe: New Evidence using National and Regional Data", mimeo, Sonoma State University.

[16] Cahuc, P. and S. Carcillo (2006), "The Shortcomings of a Partial Release of Employment Protection Laws: The Case of the 2005 French Reform", IMF Working Paper 06/301.

[17] Cahuc. P. and F. Kramarz (2004), De la précarité à la mobilité, vers une sécurité sociale professionnelle, Rapport pour le Ministre de l'Economie et des Finances, La documentation Française, available at ladocumentationfrancaise.fr/rapportspublics/054000092/index.shtml

[18] Cahuc, P. and F. Postel-Vinay (2002), "Temporary Jobs, Employment Protection and Labor Market Performance", Labor Economics 9, 63-91.

[19] Cahuc, P., F. Postel-Vinay and J. M. Robin (2006), "Wage Bargaining with On-TheJob Search: A Structural Econometric Model", Econometrica 74, 323-64.

[20] Costain, J., Juan F. Jimeno and Carlos Thomas (2010), "Employment Fluctutations in a Dual Labor Market", Banco de España, Working Paper 1013.

[21] Eurostat (2009), Youth in Europe, Publications Office of the European Union, Luxembourg.

[22] Garcia-Perez, J. I. (2009), "¿Qué Efectos Tendría un Contrato Único sobre la Protección del Empleo?", in J. Dolado and F. Felgueroso (eds.), Propuesta de Reactivación Laboral en España, Fedea, Madrid, available at crisis09.es/ebook_propuesta_laboral/Propuesta_reactivacion_laboral_art_6.pdf

[23] Garcia-Perez, J. I. and Y. F. Rebollo-Sanz (2009), "Do Wage Subsidies Affect the Subsequent Employment Stability of Permanent Workers?: The Case of Spain", Moneda y Crédito 228, 65-102.

[24] Garibaldi, P. (1998), "Job Flow Dynamics and Firing Restrictions", European Economic Review 42, 245-75. 
[25] Ichino, A. and Riphahn, R. (2005), "The Effect of Employment Protection on Worker Effort - A Comparison of Absenteeism During and After Probation", Journal of the European Economic Association 3, 120-143.

[26] Ichino, P. et al. (2009), "Disegno di Legge per la Transizione a un Regime di Flexicurity, n. 1481", 25 March. Synthesis in English at pietroichino.it/?p=3536.

[27] Kramarz, F. and M. L. Michaud (2010), "The Shape of Hiring and Separation Costs", Labour Economics 17, 27-37.

[28] Kramarz, F. and T. Philippon (2001), "The Impact of Differential Payroll Tax Subsidies on Minimum Wage Employment", Journal of Public Economics 82, 115-146.

[29] Layard, R., S. Nickell, and R. Jackman (1991), Unemployment. Macroeconomic Performance and the Labor Market, Oxford University Press, Oxford.

[30] Lazear, E.(1990), "Job Security Provisions and Employment", Quarterly Journal of Economics, 105, 699-726.

[31] L'Haridon, O. and F. Malherbet (2009), "Employment Protection Reform in Search Economies", European Economic Review 53, 255-273.

[32] Ljungqvist, L. (2002), "How Do Layoff Costs Affect Employment?", Economic Journal 112, 2002, 829-853.

[33] Lopez-Garcia, M. A. (2004), "Housing, Prices and Tax Policy in Spain", Spanish Economic Review 6, 29-52.

[34] Malcomson, J. M. (1999), "Individual Employment Contracts", in O. Ashenfelter and D. Card (eds.), Handbook of Labor Economics, ch. 35, 2291-2372.

[35] Mortensen, D. T. and C. A. Pissarides (1994), "Job Creation and Job Destruction in the Theory of Unemployment", Review of Economic Studies 61, 397-415.

[36] Organisation for Economic Cooperation and Development (OECD) (2004), Employment Outlook, OECD, Paris.

[37] OECD (2005), Employment Outlook, OECD, Paris.

[38] Oswald, A. J. (1999), "The Housing Market and Europe's Unemployment: A NonTechnical Paper", mimeo, University of Warwick.

[39] Petrongolo, B. and C. A. Pissarides (2001), "Looking into the Black Box: A Survey of Matching Functions", Journal of Economic Literature 39, 390-431. 
[40] Pissarides, C. A. (2000), Equilibrium Unemployment Theory, $2^{\text {nd }}$ ed., The MIT Press, Cambridge, MA.

[41] Rupert, P. and E. Wasmer (2009), "Housing and the Labor Market: Time to Move and Aggregate Unemployment", mimeo, Sciences-Po, Paris.

[42] Saint-Paul, G. (1996), Dual Labor Markets, The MIT Press, Cambridge, MA.

[43] Saint-Paul, G. (1997), "Is Labour Rigidity Harming Europe's Competitiveness? The Effect of Job Protection on the Pattern of Trade and Welfare", European Economic Review 41, 499-506.

[44] Saint-Paul, G. (2000), The Political Economy of Labour Market Institutions, Oxford University Press, Oxford.

[45] Sala, H., J. I. Silva, and M. E. Toledo (2009), "Flexibility at the Margin and Labor Market Volatility in OECD Countries", SSRN, available at: ssrn.com/abstract $=1377909$.

[46] Vandenbrande et al. (2006), Mobility in Europe, Office for Official Publications of the European Union, Luxembourg.

[47] Visser, J. (2009), "ICTWSS: Database on Institutional Characteristics of Trade Unions, Wage Setting, State Intervention and Social Pacts in 34 countries between 1960 and 2007", Amsterdam Institute for Advanced Studies (www.uva-aias.net/208).

[48] Wasmer, E. (1999), "Competition for Jobs in a Growing Economy and the Emergence of Dualism in Employment", Economic Journal 109, 349-371. 


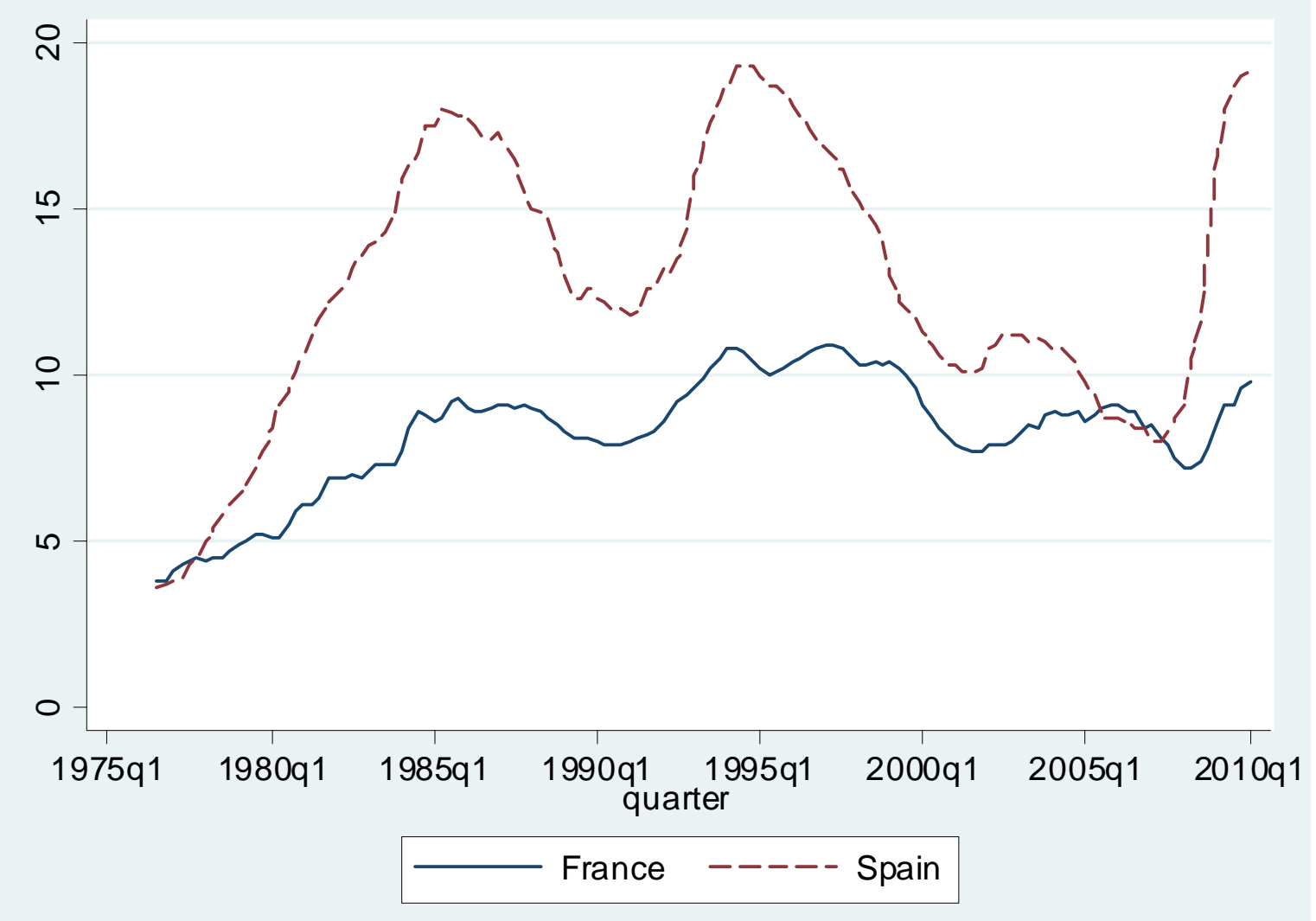

Figure 1: Unemployment rate in France and Spain, 1976-2010 
Table 1: Labor market evolutions in France and Spain

\begin{tabular}{|c|c|c|c|c|}
\hline \multicolumn{2}{|l|}{ Levels (\%) } & \multirow{2}{*}{$\begin{array}{r}1998: 1 \\
10.3\end{array}$} & \multirow{2}{*}{$\begin{array}{r}2007: 4 \\
7.5\end{array}$} & \multirow{2}{*}{$\begin{array}{r}2009: 4 \\
9.7\end{array}$} \\
\hline 1. Unemployment & France & & & \\
\hline & Spain & 15.2 & 8.7 & 18.9 \\
\hline 2. Fixed-term employment ${ }^{1}$ & France & 13.8 & 14.3 & 13.1 \\
\hline & Spain & 33.3 & 30.9 & 25.1 \\
\hline 3. Hours of work ${ }^{2}$ & France & 40.7 & 37.7 & 37.4 \\
\hline & Spain & 38.8 & 39.0 & 39.1 \\
\hline \multicolumn{2}{|l|}{ Annual growth rates $(\%)^{3}$} & & 1998:1-2007:4 & 2008:1-2009:4 \\
\hline 4. Gross Domestic Product & France & & 2.3 & -1.1 \\
\hline & Spain & & 3.7 & -2.2 \\
\hline \multirow[t]{2}{*}{ 5. Labor force } & France & & 0.8 & 0.9 \\
\hline & Spain & & 3.3 & 1.3 \\
\hline \multirow[t]{2}{*}{ 6. Employment } & France & & 1.1 & -0.3 \\
\hline & Spain & & 4.2 & -4.6 \\
\hline \multicolumn{5}{|l|}{ 7. Private non-agricultural employees: } \\
\hline \multirow{2}{*}{ (a) Total } & France & & 1.5 & -1.6 \\
\hline & Spain & & 5.6 & -5.7 \\
\hline \multirow[t]{2}{*}{ (b) Construction } & France & & 2.4 & -1.8 \\
\hline & Spain & & 8.1 & -19.8 \\
\hline \multirow[t]{2}{*}{ (c) Manufacturing } & France & & -0.7 & -3.2 \\
\hline & Spain & & 2.0 & -10.8 \\
\hline \multirow[t]{2}{*}{ (d) Market services } & France & & 2.2 & -1.1 \\
\hline & Spain & & 6.8 & -0.9 \\
\hline \multirow[t]{2}{*}{ 8. Real hourly earnings ${ }^{4}$} & France & & 1.3 & 1.1 \\
\hline & Spain & & 0.3 & 2.5 \\
\hline \multirow[t]{2}{*}{ 9. Hiring on temporary contracts ${ }^{5}$} & France & & 78.6 & 83.3 \\
\hline & Spain & & 90.5 & 89.6 \\
\hline
\end{tabular}

Notes: ${ }^{1}$ As a share of employees. ${ }^{2}$ Full-time employees. ${ }^{3}$ Computed as annual rates of endof-period on start-of period quarterly levels. ${ }^{4}$ Deflated by GDP Deflator, seasonally adjusted. ${ }^{5}$ Average share over the corresponding period.

Sources: (1),(4)-(6), OECD Economic Outlook Database (www.oecd.org); (2),(3) Eurostat Statistics Database (epp.eurostat.ec.europa.eu); (7), INSEE BDM Macroeconomic Database (www.bdm.insee.fr) for France and INE, Encuesta de Población Activa (www.ine.es) for Spain; (8) OECD Main Economic Indicators Database (www.oecd.org), (9) ACOSS (www.acoss.urssaf.fr) for France and Ministerio de Trabajo e Inmigración, Boletín de Estadísticas Laborales (www.mtin.es). 


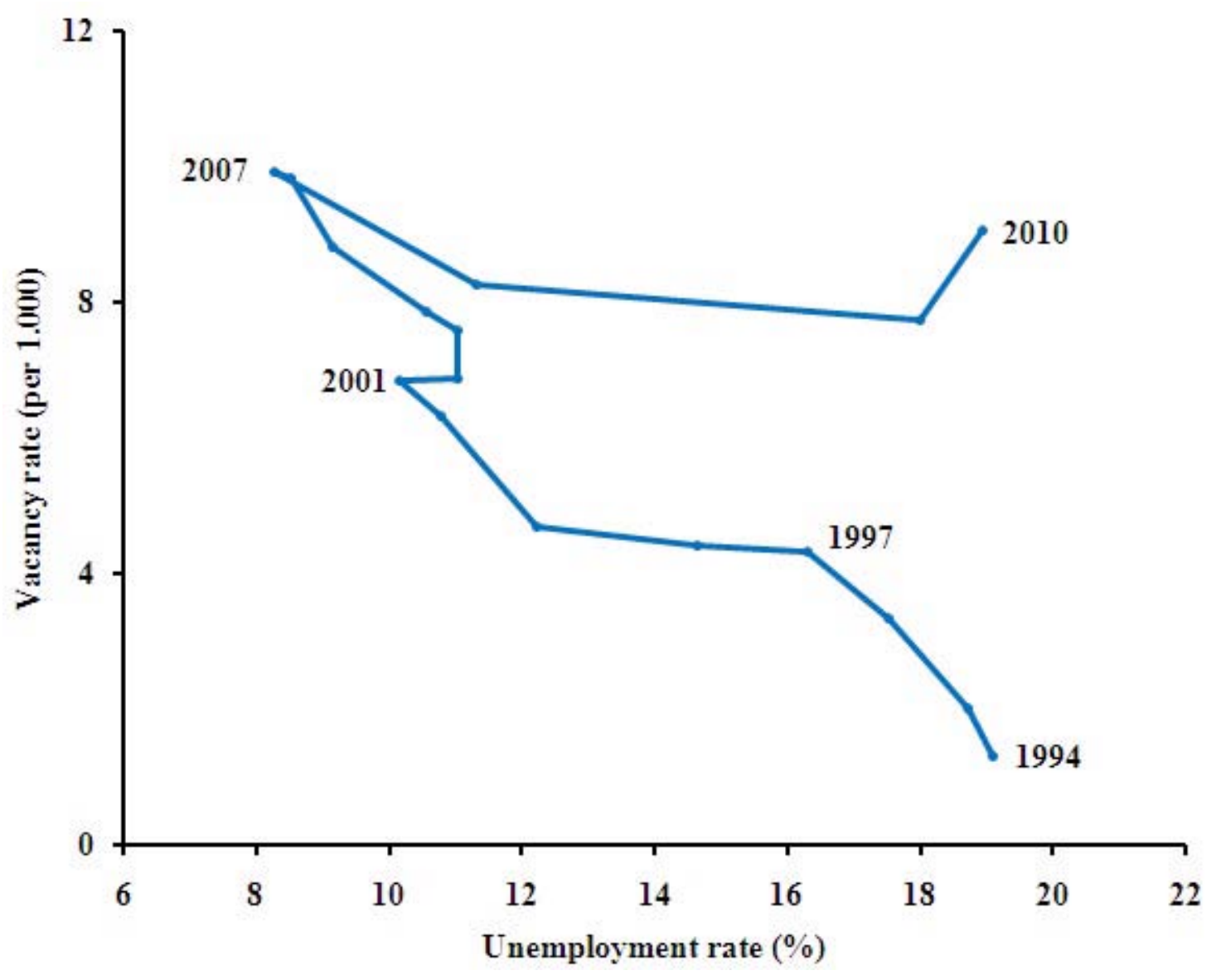

Figure 2: Beverigde curve for Spain 


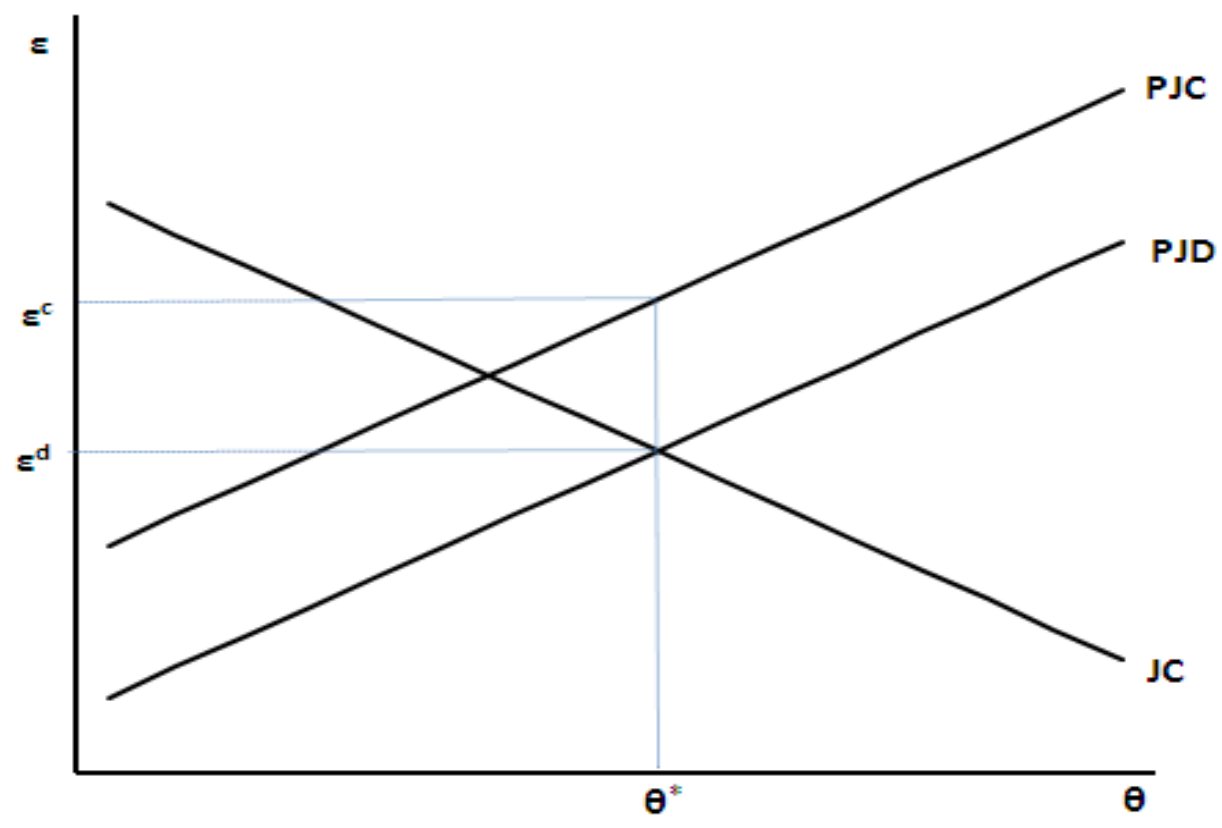

Figure 3: Labor market equilibrium 


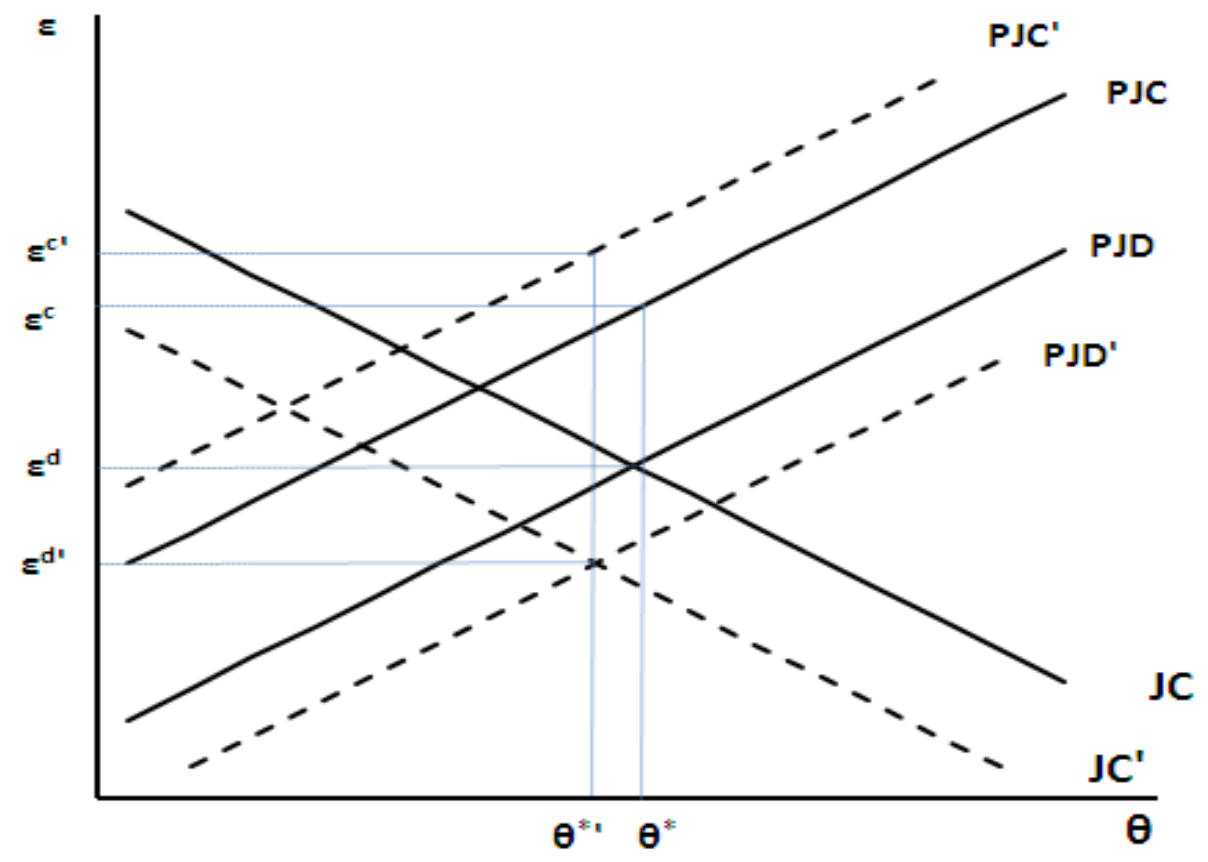

Figure 4: Effects of an increase in the firing cost $(f)$ 


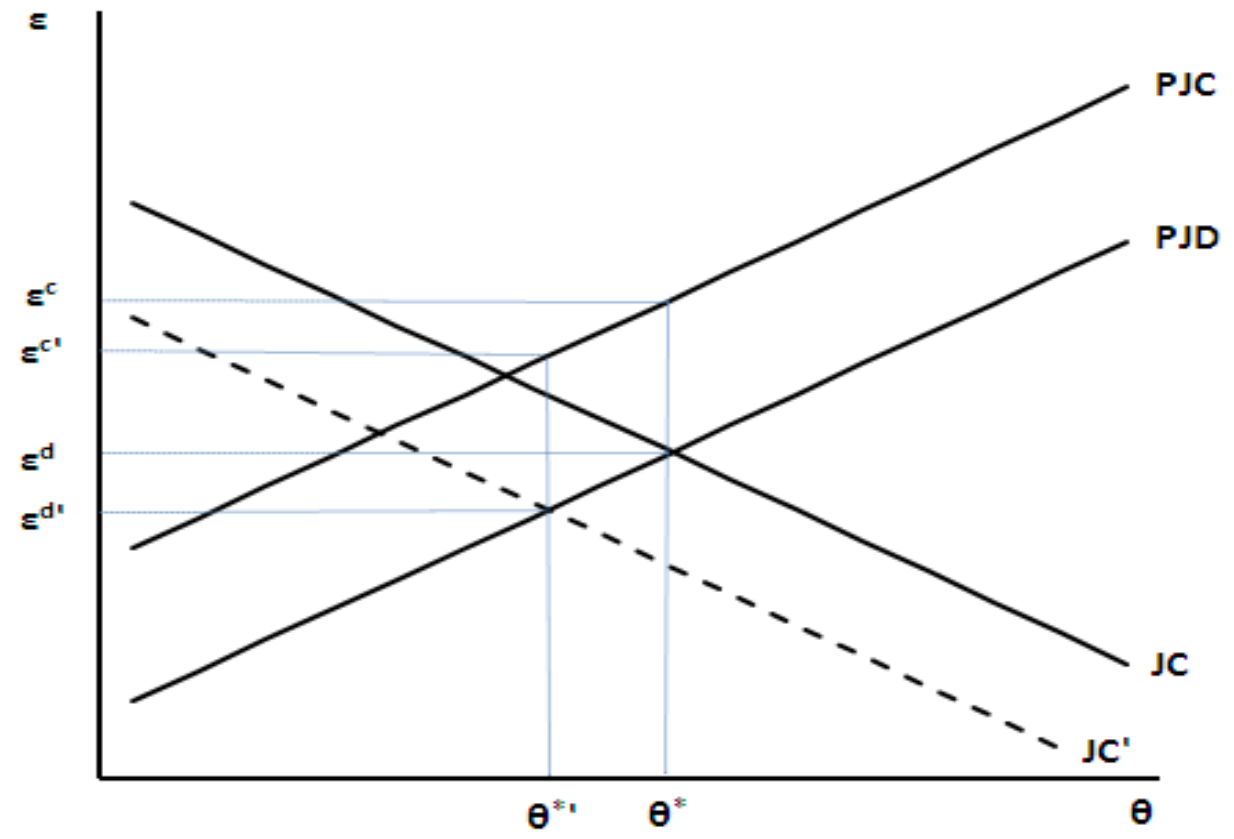

Figure 5: Effects of a reduction in the proportion hires on temporary contracts $(p)$ 
Table 2: Calibrated and estimated parameters ${ }^{1}$

France Spain

Standard parameters:

Interest rate

$\begin{array}{lll}r & 0.01 & 0.01\end{array}$

Matching function elasticity

$\begin{array}{lll}\alpha & 0.50 & 0.50\end{array}$

Worker bargaining power

$\beta \quad 0.50 \quad 0.50$

Institutional parameters:

$\begin{array}{lllll}\text { Unemployment benefit replacemente rate } & b & 0.55 & 0.58\end{array}$

Severance pay for permanent employees

f $\quad 1.33 \quad 2.00$

Dual labor market flow rates:

$\begin{array}{lllll}\text { Probability of hiring into a temporary job } & p & 0.85 & 0.91\end{array}$

$\begin{array}{lllll}\text { Probability of temporary contract ending } & \lambda & 0.88 & 0.88\end{array}$

Parameters estimated by indirect inference:

Cost of keeping jobs vacant

$\begin{array}{lll}h & 0.50 & 0.25\end{array}$

Matching efficiency level in expansion

$m_{0} \quad 1.50 \quad 2.50$

Matching efficiency level in recession

$m_{0}^{\prime} \quad 1.50 \quad 1.50$

Incidence rate of productivity shocks

$\mu \quad 0.04 \quad 0.09$

Lower bound of productivity shock

$\begin{array}{lll}\varepsilon & 0.00 & 0.00\end{array}$

$\begin{array}{llll}\text { Shocks multiplicative shift factor in recession } & \gamma & 0.90 & 0.87\end{array}$

Advance notice rate

$\sigma \quad 0.75 \quad 4.30$

${ }^{1}$ Reference period: 2005:1-2007:4. 
Table 3: Simulation results

\begin{tabular}{|c|c|c|c|c|}
\hline & & $\begin{array}{l}\text { Unemployment } \\
\text { rate }\end{array}$ & $\begin{array}{c}\text { Perm. jobs } \\
\text { destruction } \\
\text { rate }\end{array}$ & $\begin{array}{c}\text { Temporary } \\
\text { employment } \\
\text { rate }\end{array}$ \\
\hline \multicolumn{5}{|c|}{ France - Expansion } \\
\hline 1. & Data & 0.0860 & 0.0150 & 0.1260 \\
\hline \multirow[t]{2}{*}{2.} & Model & 0.0854 & 0.0305 & 0.1137 \\
\hline & \multicolumn{4}{|c|}{ France - Recession } \\
\hline 3. & Data & 0.0980 & 0.0130 & 0.1250 \\
\hline \multirow[t]{2}{*}{4.} & Model & 0.0973 & 0.0304 & 0.1145 \\
\hline & \multicolumn{4}{|c|}{ Spain - Expansion } \\
\hline 5. & Data & 0.1020 & 0.0470 & 0.3330 \\
\hline \multirow[t]{2}{*}{6.} & Model & 0.1022 & 0.0655 & 0.3300 \\
\hline & \multicolumn{4}{|c|}{ Spain - Recession } \\
\hline 7 . & Data & 0.1790 & 0.0400 & 0.2700 \\
\hline 8. & Baseline & 0.1736 & 0.0641 & 0.3793 \\
\hline 9. & Alternative & 0.1765 & 0.0611 & 0.2796 \\
\hline
\end{tabular}


Table 4: Differential increase in unemployment in Spain induced by the recession explained by differences with France in the alternative simulation (percentage points)

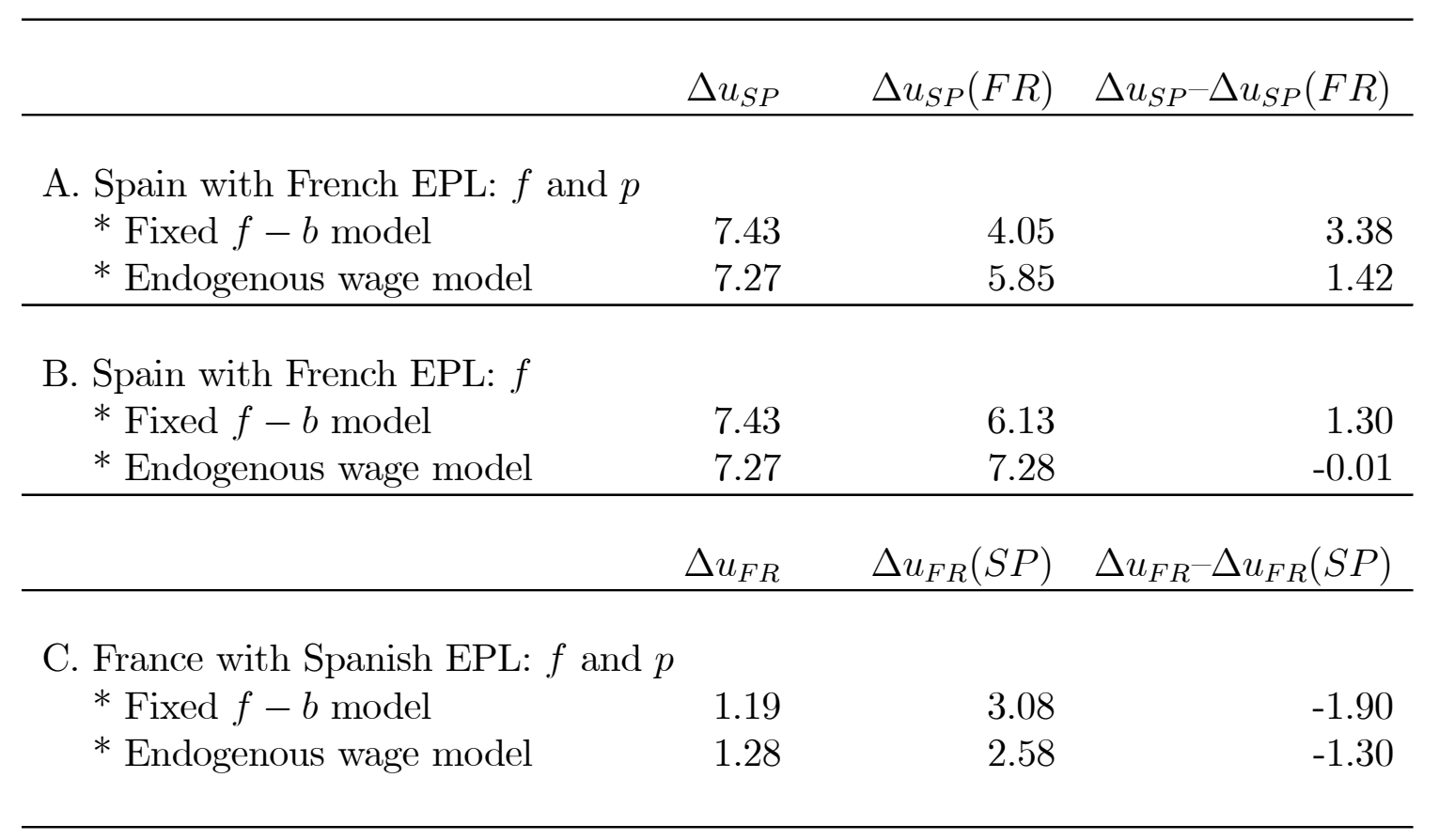

Note: $\Delta u_{S P}$ denotes the change in unemployment explained by the model simulated for the Spanish economy and $\Delta u_{S P}(F R)$ the change in unemployment explained by the model simulated for the Spanish economy with the indicated set of parameter values corresponding to the simulated French economy. The mirror definitions apply to $\Delta u_{F R}$ and $\Delta u_{F R}(S P)$. 


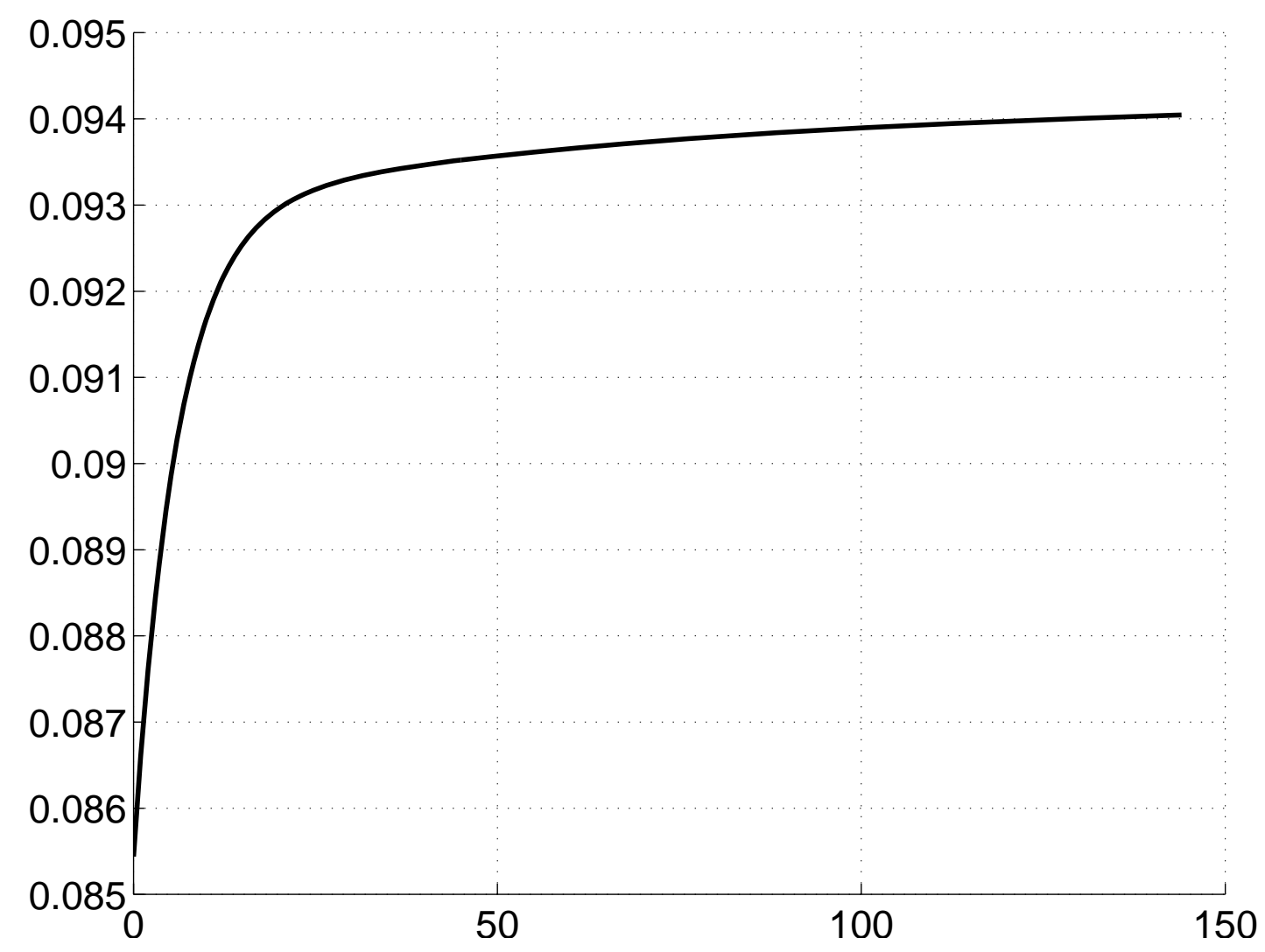

Figure 6: Simulated change in unemployment rate in France (period in weeks) 


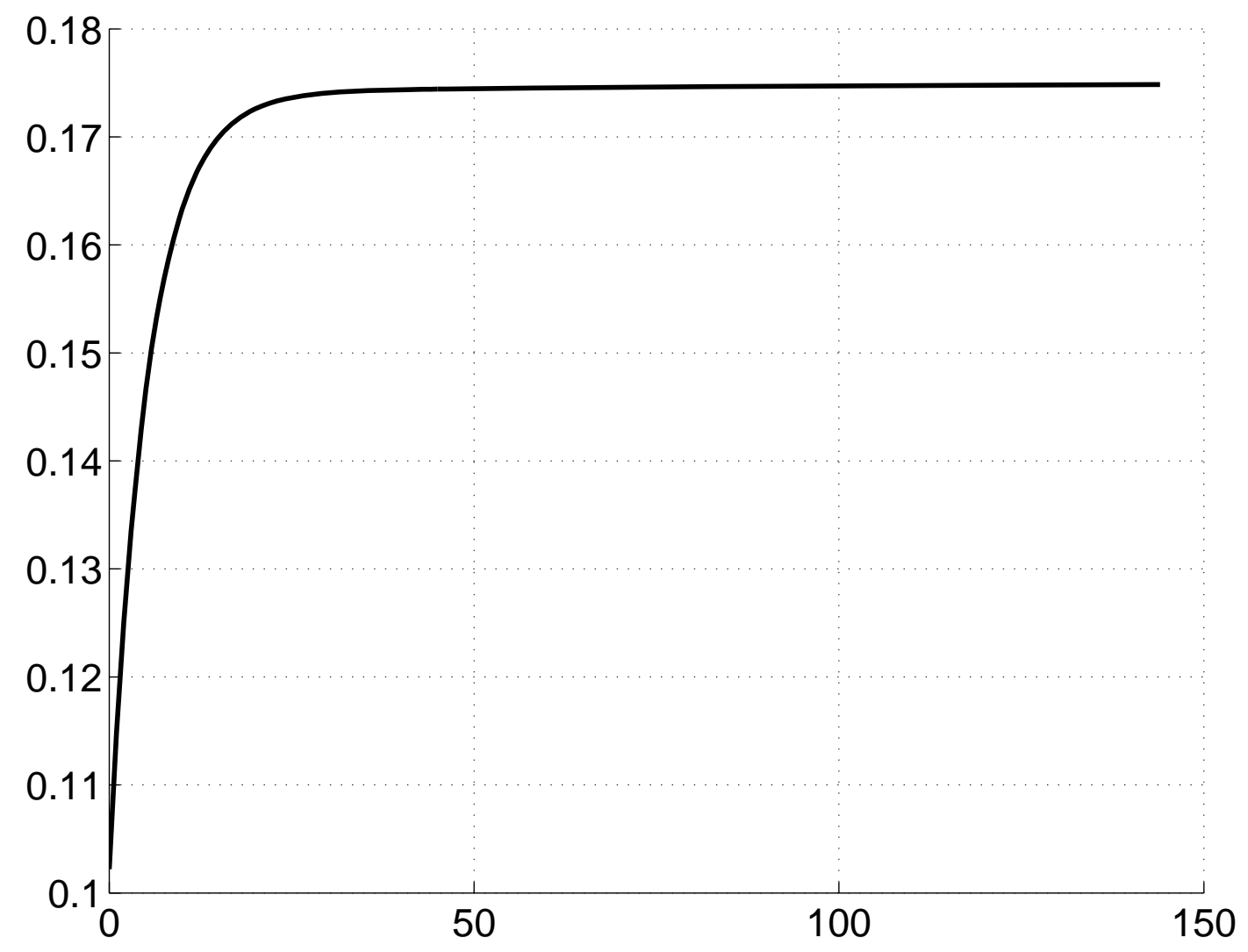

Figure 7: Simulated change in unemployment rate in Spain (period in weeks) 


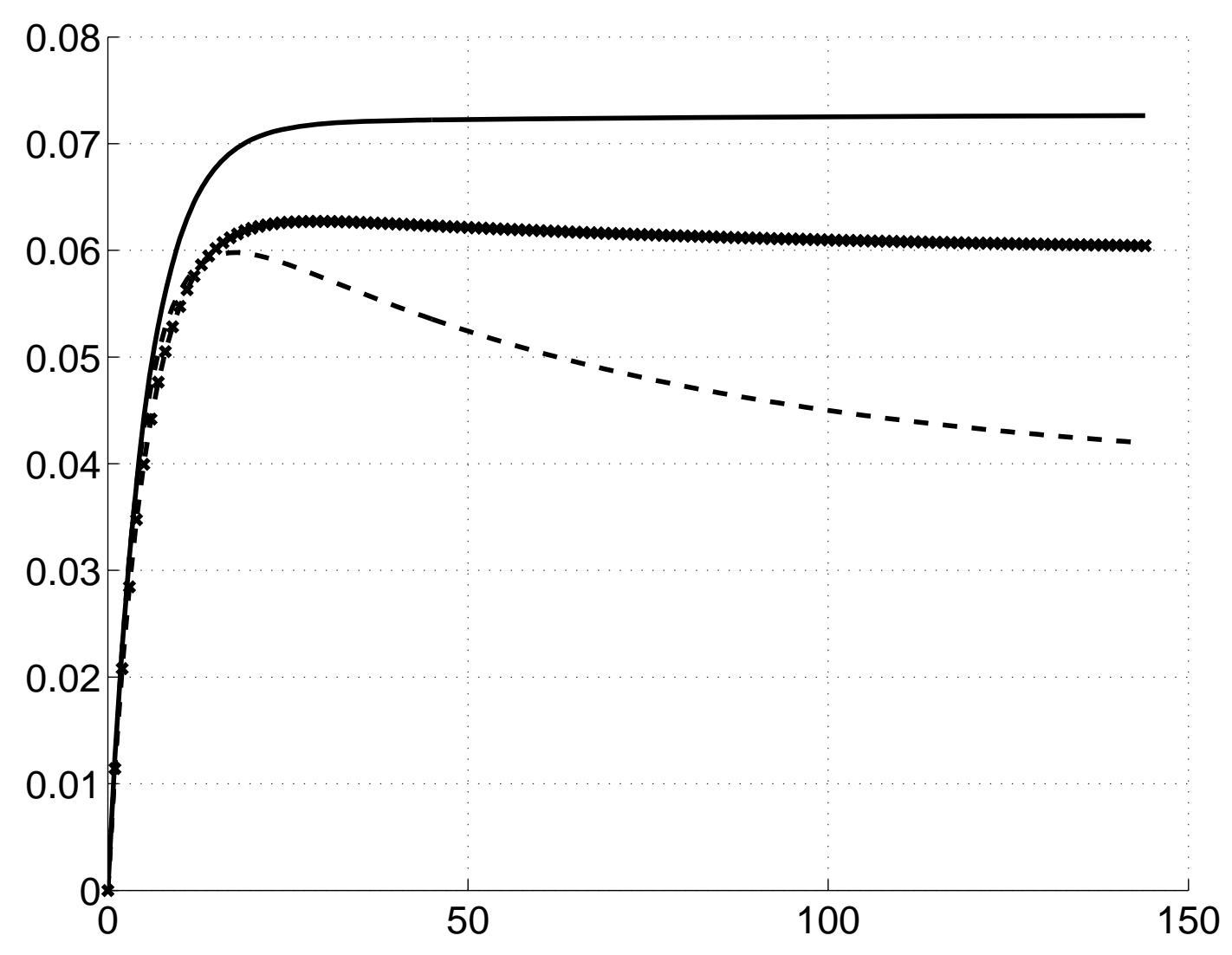

Figure 8: Change in unemployment rate in Spain with Spanish EPL (solid line), with French layoff costs and French regulation of temporary jobs (dotted line), with French layoff costs and Spanish regulation of temporary jobs (line with crosses), (period in weeks) 